\title{
The Variability of Money Velocity in a Generalized Cash-in-Advance Model
}

\author{
Hugo Rodríguez Mendizábal* \\ Universitat Pompeu Fabra
}

September 1, 1998

\begin{abstract}
This paper presents a general equilibrium model of money demand where the velocity of money changes in response to endogenous fluctuations in the interest rate. The parameter space can be divided into two subsets: one where velocity is constant and equal to one as in cash-in-advance models, and another one where velocity fluctuates as in Baumol (1952). Despite its simplicity, in terms of parameters to calibrate, the model performs surprisingly well. In particular, it approximates the variability of money velocity observed in the U.S. for the post-war period. The model is then used to analyze the welfare costs of inflation under uncertainty. This application calculates the errors derived from computing the costs of inflation with deterministic models. It turns out that the size of this difference is small, at least for the levels of uncertainty estimated for the U.S. economy.

JEL classification: E41

Keywords: Money Demand; Money Velocity; Cash-in-Advance;

*I would like to thank Robert E. Lucas Jr., Thomas J. Sargent and Nancy L. Stokey for all their helpful suggestions. I have also benefited from comments by Eduardo Andrade, Krishna Kumar, Wenqing Li, Gabriel Pérez Quirós, Ashok Rai, Giorgio Topa, and seminar participants at the University of Chicago. Financial support from the Bank of Spain and the Alfred P. Sloan Foundation is acknowledged. All remaining errors are my sole responsibility. E-mail address: hugo.rodriguez@econ.upf.es
\end{abstract}




\section{Introduction}

This paper presents a general equilibrium version of the models in Baumol [2] or Tobin [30] where the velocity of money is determined endogenously and changes in response to fluctuations in the interest rate. The cash-in-advance (CIA) models of Lucas [18] and Svensson [29] appear as particular cases for a subset of the parameter space.

General equilibrium models of the transaction demand for money have been generated in different ways in the literature. Jovanovic [17] presents a deterministic economy where agents have access to a productive storage technology for capital. Agents want to consume continuously but capital can only be consumed if transferred to the market at a fixed cost. Since capital perishes once removed from storage $\Gamma$ money is used to finance consumption between the dates when capital is liquidated. Another route has been taken by the so-called "shopping-time" models of money demandГsuch as the ones in Den Haan [6] ГGuidotti [14] Tand Guidotti and Végh [15]. In these models $\Gamma$ agents value consumption of goods as well as leisure a time-consuming activity. However Tincreases in real money holdings reduce the time needed for transactions. Feenstra [10] and Marshall [23] use the same idea but the cost involves goods instead of time. Finally like Rotemberg [25] TGrossman and Weiss [13] and Alvarez and Atkenson [1] $\Gamma$ agents decide on the composition of their portfolios between cash Tneeded for transactions $\Gamma$ and bonds bearing an interest rate. However $\Gamma$ the number of trips to the bank per period is fixed exogenously in these models.

CIA models can also be seen as general equilibrium versions of the BaumolTobin model of money demand with the following transactions technology: the first trip to the bank is free and the subsequent ones are prohibitively expensive. Thus $\Gamma$ the agent only goes to the bank once. This transaction technology is the basis for the unitary money velocity prediction of the simplest versions of CIA models. Two extensions have been developed in the literature to overcome this unrealistic feature. One is the introduction of a precautionary motive to hold currency as in Lucas [19] and Svensson [29] by changing the information structure of the model. With this new setup $\Gamma$ information about the current state of the economy is revealed only after the agents make their decisions on money holdings. Once uncertainty is resolved there will be states of the world where all cash balances are not spent and the velocity of money can vary. The second extension involves the introduction of a second good whose consumption does not need to be paid for with 
cash as in Lucas and Stokey [21]. In these models Tmoney velocity changes because the relative proportions of consumption in cash goods (goods whose consumption has to be paid for with cash) and in credit goods (goods whose consumption does not need to be purchased with cash) change over time depending on the economic fundamentals. ${ }^{1}$ HoweverTas it is shown in Hodrick et al. [16] nneither interpretation can explain the variability of money velocity observed in the data.

The model developed here extends conventional CIA models in one dimension; it allows agents to economize on their cash holdings by changing the number of trips to the bank in response to changes in the interest rate. As in conventional CIA models Tmarkets open sequentially. In the simplest version of the model Tan asset market opens first at the beginning of the period once the state of the economy is realized. In this market the agent deposits his initial wealth in an illiquid bond and contracts successive withdrawals of money that he will use to finance consumption during that period. There is a fixed transaction cost per withdrawal (except for the first one which is free) equal to a proportion $k$ of current nominal output. Interest rates are determined at the beginning of the period and are paid at the end of the period on average bond holdings. During the second subperiod $\Gamma$ a product market opens and the agent finances consumption with the successive money withdrawals. For values of the parameter $k$ that are small enough $\Gamma$ the Baumol's inventory-theoretic considerations that are responsible for variations in money velocity in response to endogenous changes in the interest rate will appear here too.

The timing conventions in Svensson [29] which give rise to a precautionary demand for money can also be included. In this case $\mathrm{Tthe}$ asset market opens at the end of each period. In this market Thouseholds decide on bond holdings and size of withdrawals to be used for consumption next period. When money holdings are decided for the next period 5 the velocity of circulation of money is regarded as a random variable which depends on the state of the economy to be realized the following period. This will imply a precautionary demand for money. At the beginning of the following period the state of the economy is realized and the product market opens. The household finances his current consumption with the withdrawals whose sizes were contracted the period before. At the time the asset market opens again Tinterest rates

\footnotetext{
${ }^{1}$ Schreft [26] develops an overlapping generations model with a physical setup similar to the one presented here where the mix of cash and credit goods is determined endogenously.
} 
on average bond holdings and brokerage fees are paid and the process starts over.

Two applications of these models will be pursued here. The first one deals with approximating the sample moments of money velocity and nominal interest rate estimated from U.S. data. Despite its simplicity in terms of the number of parameters to calibrate $\mathrm{T}$ the model performs surprisingly well.

The second exercise consists of analyzing the welfare cost of inflation under uncertainty. Papers like Lucas [20] have estimated these costs using deterministic models. ${ }^{2}$ A question which naturally arises is how large of an error is one making for not including uncertainty. It turns out that computations derived from deterministic models are very close to those derived from stochastic ones even for high rates of money growth. Therefore $i$ it seems that uncertainty does not play a large role as an element of the welfare cost of inflation. $^{3}$

The next two sections describe the models. Section 2 deals with the transactions demand for money. Timing will be as in Lucas [18]. Precautionary motives to hold currency are introduced in section 3 . There the sequence of markets is as in Svensson [29]. Section 4 presents the empirical applications and section 5 concludes and addresses future applications of the model.

\section{A Transaction Demand for Money}

The setup of this economy is similar to Lucas [18]. HenceforthГI will refer to the following model as Lucas Model. Time is discrete. Uncertainty Tnamely the output to be produced and the injection of new money is resolved at the beginning of the period $\Gamma$ before any decision is taken. There is a continuum of infinitely lived households indexed by $h \Gamma h \in H=[0,1]$. Every day $\Gamma$ a good is produced in $J$ different varieties or colors indexed by $j=(1, \ldots, J) \Gamma$ with items of each color produced and sold in spatially separated factoriesstores. These firms are distributed evenly around a circle of length one in $J$ locations or villages. Contemporaneous preferences of the $h$-th household

\footnotetext{
${ }^{2}$ Dotsey and Ireland [9] also use a deterministic model, similar to the one in Schreft [26], where the costs of inflation arise from distortions in agents' decisions.

${ }^{3}$ A similar result was obtained in Den Haan [6] where it is shown that although reducing the money supply on average at the rate of time preference is not optimal in the presence of uncertainty, it is very close to the optimal policy.
} 
over all possible varieties of the good are summarized by the function

$$
V\left(c_{1 t}^{h}, \ldots, c_{J t}^{h}\right)=u\left[\prod_{j=1}^{J}\left(\frac{c_{j t}^{h}}{\alpha_{j}}\right)^{\alpha_{j}}\right],
$$

with $c_{j t}^{h}$ being consumption of household $h$ of variety $j$ during period $t$. The function $u: R_{+} \rightarrow R$ is continuous $\Gamma$ twice differentiable $\Gamma$ strictly increasing and strictly concave. Also $\sum_{j=1}^{J} \alpha_{j}=1$ and $\alpha_{j}>0$ all $j$. Define $c_{t}^{h}=\sum_{j=1}^{J} c_{j t}^{h}$. Since in equilibrium relative prices will be one across colors it turns out that

$$
\frac{c_{j t}^{h}}{c_{t}^{h}}=\alpha_{j},
$$

so that

$$
V\left(c_{1 t}^{h}, \ldots, c_{J t}^{h}\right)=u\left(c_{t}^{h}\right) .
$$

Each household is composed of a worker-shopper pair. The couple lives next to the location where the worker goes to work. This means that a proportion $\alpha_{j}$ of the households lives in location $j$. They own the firm in that location. The worker is endowed with a unit of labor which yields $y_{t}$ units of any color at the factory. The shopper on the other hand dedicates his time to visit all the shops around the circle to buy the other varieties of the good. It is assumed that he can move clockwise only. If $\Gamma$ as in Lucas [18] Tthere is limited communication among the stores so it is costly for them to verify each shopper's credit history there is an incentive in this economy to use currency as a means to save on information costs. In Lucas [18] $\Gamma$ at the beginning of the period the shopper is issued claims to $y_{t}$ units of consumption that he uses to buy goods. These claims are redistributed to the workers at the end of the period and the process starts all over again. I am going to modify this monetary arrangement in order to motivate a transaction technology à la Baumol within each period.

The introduction of money in this model is as follows. Assume that in order to distribute money to the households $\Gamma$ a bank is created in each location. Firms and households have accounts at the bank in their home location. The period begins with shoppers at the bank in their respective villages. Household $h$ starts with initial nominal wealth $W_{t}^{h}$. Then an asset market opens where the shopper decides on an initial deposit in the bank plus the number and sizes of money withdrawals that he will make while going around the circle and will use to finance his consumption in that period. 
These withdrawals are charged to the initial bond holdings. Each withdrawal (except for the first one which is free) costs a fee $\widetilde{K}_{t}$ to be specified below. These fees are paid to the bank at the end of the period. The shopper keeps visiting firms around the circle and buying the consumption goods until he runs out of money in some store. Then he visits the bank in that location and claims the next withdrawal. After withdrawing the money the shopper returns to the product market to buy goods. He will continue to do this the number of times contracted previously. As the agents buy the goods $\Gamma$ the firms take the money back to the bank and deposit it there. Interest is paid at the end of the period on average deposits.

The nature of the fee is explained as follows. When an agent wants to make a withdrawal other than the first one $\Gamma$ he will do it in a bank where he does not have an account. In that case $\Gamma$ his bank will need to hire a proportion $\tilde{k}$ of workers from the shopper's location. These workers will do all the necessary bookkeeping for that transaction. Since banks know from the beginning of the period how many withdrawals the shoppers from their villages are going to make $\mathrm{T}$ they can also hire these workers at the beginning of the period. This is the origin of the fee which serves to pay the wages of the workers at the bank. At the end of the period shoppers pay the fees to banks $\Gamma$ banks pay interest on average deposits to firms and households and wages to workers Tand firms pay wages to workers and dividends to households. New money enters the system through a monetary transfer $H_{t+1}$ which is given to households at the beginning of the next period Tand the process starts all over again.

\subsection{The Household's Problem}

Each period Thousehold $h$ has to choose how much to consume and how to finance this consumption $\Gamma$ that is $\Gamma$ how many times to go to the bank and how much money to withdraw in each trip. Assume the shopper spends at a constant rate around the circle. Let $N_{t}^{h}$ be the contracted number of trips to the bank within period $t$. Denote by $M_{t}^{h}(s)$ the size of the $s$-th withdrawal with $s=1, \ldots, N_{t}^{h}$. Also let $\Delta t_{s}$ be the length of the time interval between trips $s$ and $s+1$. The total size of withdrawals in period $t$ is equal to

$$
\widehat{M}_{t}^{h}=\sum_{s=1}^{N_{t}^{h}} M_{t}^{h}(s) .
$$


If $B_{t}^{h}$ denotes initial bond holdings $\Gamma$ it must be the case that

$$
B_{t}^{h}+M_{t}^{h}(1) \leq W_{t}^{h},
$$

while average account balances equal

$$
\bar{B}_{t}^{h}=B_{t}^{h}-\sum_{s=2}^{N_{t}^{h}}\left[\Delta t_{s} \sum_{r=2}^{s} M_{t}^{h}(r)\right] .
$$

In the product market the agent uses the money obtained from the trips to the bank to finance consumption of that period $\Gamma$ that is $\Gamma$

$$
P_{t} c_{t}^{h} \leq \widehat{M}_{t}^{h}
$$

Finally Wwealth evolves as

$$
W_{t+1}^{h}=W_{t}^{h}+H_{t+1}^{h}+S_{t}^{h}+D_{t}^{h}+i_{t} \bar{B}_{t}^{h}-P_{t} c_{t}^{h}-\left(N_{t}^{h}-1\right) \widetilde{K}_{t},
$$

where $H_{t+1}^{h}$ is the exogenous money transfer $\Gamma S_{t}^{h}$ are the wages received either from firms or banks Tand $D_{t}^{h}$ is equal to dividend earnings. The next proposition ensures that trips to the bank will be evenly spaced so that the size of withdrawals within each period are equal. This is because of the assumption that the household spends at a constant rate throughout the period. Thus $\Gamma$ once the number of trips to the bank for that period has been determined Tthe opportunity cost of holding money is minimized only when the withdrawals are evenly spaced within the period.

Proposition 1. For a given $N_{t}^{h}$ Tit is optimal to set $M_{t}^{h}(r)=M_{t}^{h}$ so that $\widehat{M}_{t}^{h}=N_{t}^{h} M_{t}^{h}$.

Proof. See Appendix A.2.

Then Tgiven the processes for $\left\{P_{t}, i_{t}, H_{t+1}^{h}, S_{t}^{h}, D_{t}^{h}, \widetilde{K}_{t}\right\}_{t=0}^{\infty}$ and initial wealth $W_{0}$ Tthe household $h$ chooses sequences $\left\{c_{t}^{h}, M_{t}^{h}, B_{t}^{h}, N_{t}^{h}\right\}_{t=0}^{\infty}$ to maximize expected lifetime utility

$$
E_{0}\left[\sum_{t=0}^{\infty} \beta^{t} u\left(c_{t}^{h}\right)\right],
$$

where $0<\beta<1$ is a discount factor $\Gamma$ subject to a generalized cash-in-advance (GCIA) constraint $\Gamma$

$$
P_{t} c_{t}^{h} \leq N_{t}^{h} M_{t}^{h}
$$


a wealth constraint $\Gamma$

$$
B_{t}^{h}+M_{t}^{h} \leq W_{t}^{h}
$$

nonnegativity constraints $\Gamma$

$$
c_{t}^{h} \geq 0, M_{t}^{h} \geq 0
$$

and the constraint that they visit the bank at least once each periodI ${ }^{4}$

$$
N_{t}^{h} \geq 1
$$

Finally Twealth evolves as (1) where average account balances $\Gamma \bar{B}_{t}^{h}$ Tare equal to

$$
\bar{B}_{t}^{h}=B_{t}^{h}-\frac{M_{t}^{h}}{N_{t}^{h}} \sum_{j=1}^{N_{t}^{h}-1} j=B_{t}^{h}-\frac{N_{t}^{h}-1}{2} M_{t}^{h}
$$

\subsection{The Bank's Problem}

The bank in location $j$ makes interest payments on average deposits by the firm in that location $\Gamma B_{t}^{j} \Gamma$ and by households $\Gamma B_{t}^{h} \Gamma h \in A^{j}$ where

$$
A^{j}=\left[\sum_{k=0}^{j-1} \alpha^{k}, \sum_{k=0}^{j} \alpha^{k}\right]
$$

is the mass of people living in location $j(j=1, \ldots, J) \Gamma$ with $\alpha^{0}=0$. The bank also receives fees from shoppers and pays wages to workers. Although there is one bank per location $\Gamma$ it is assumed that potential entrants drive existing banks' profits to zero. Therefore $\Gamma$ for bank $j$ it must be the case that

$$
\widetilde{K_{t}} \int_{A^{j}}\left(N_{t}^{h}-1\right) d h=i_{t} \int_{A^{j}} \bar{B}_{t}^{h} d h+i_{t} \bar{B}_{t}^{j}+\widetilde{k} \int_{A^{j}} S_{t}^{h}\left(N_{t}^{h}-1\right) d h .
$$

The left side of expression (7) represents the fees collected from households. The right side starts with the total interest paid to households Tfollowed by interest paid to firm $j$ on average deposits and finally the third term refers to total wages to bank workers.

\footnotetext{
${ }^{4}$ For tractability the integer constraint on $N_{t}^{h}$ is ignored throughout the paper.
} 


\subsection{The Firm's Problem}

The problem faced by each firm is as follows. They just produce a color of the good Treceive the interest on average deposits from banks Tand pay wages to workers and dividends to households living in their location. They also have to decide when to go to the bank to deposit the money they receive from shoppers. It is assumed that in doing so they also have to dedicate a fraction $\widetilde{k}$ of the labor force to cash management duties. ${ }^{5}$ For a competitive firm in location $j$ Tzero profits imply:

$$
\begin{gathered}
i_{t} \bar{B}_{t}^{j}+P_{t} y_{t} \int_{A^{j}}\left[1-\left(N_{t}^{j}-1\right) \tilde{k}-\left(N_{t}^{h}-1\right) \tilde{k}\right] d h= \\
\int_{A^{j}} D_{t}^{h} d h+\int_{A^{j}} S_{t}^{h}\left[1-\left(N_{t}^{h}-1\right) \tilde{k}\right] d h,
\end{gathered}
$$

where $N_{t}^{j}$ is the number of firm's deposits in the bankTand

$$
\bar{B}_{t}^{j}=\frac{M_{t}^{j}}{N_{t}^{j}} \sum_{s=2}^{N_{t}^{j}} s=\frac{N_{t}^{j}-1}{2} M_{t}^{j}
$$

is the firm's average account balance. The second term on the left side represents total production after labor has been hired by banks as well as used for the firm's cash management.

Under the assumption that all agents are identical $\Gamma$ it is possible to look at the representative agent version of this economy. This is done in the next subsection. It is easy to see that the fee will be equal to the value of labor services or $\widetilde{K_{t}}=\tilde{k} P_{t} y_{t}$. Then firms' decisions about when to deposit money in the bank are symmetric to households' decisions about when to withdraw it so that they will make the same number of trips. Also agent economy

$$
S_{t}+D_{t}=P_{t} y_{t}+i_{t} \sum_{j=1}^{J} \bar{B}_{t}^{j}-\left(N_{t}-1\right) \tilde{k} P_{t} y_{t}=P_{t} y_{t}+i_{t} \bar{B}_{t}^{a}-\left(N_{t}-1\right) \tilde{k} P_{t} y_{t}
$$

where $y_{t}=\sum_{j=1}^{J} y_{t}^{j}$ Tand $\bar{B}_{t}^{a}$ is the firms' aggregate average account balances. These are taken as given by the agents when making their decisions. Notice

\footnotetext{
${ }^{5}$ From the previous proposition, the firm will also space the deposits evenly within the period.
} 
that in the aggregate $\Gamma$ average account balances in the bank are zero since deposits by firms correspond with withdrawals by agents. However Tat the individual level there are incentives to go several times to the bank in order to save on foregone interest earnings.

\subsection{The Representative Agent Economy}

There are two sources of uncertainty in this endowment economy. Real output $\left(y_{t}\right)$ grows at an exogenous $\Gamma$ stochastic rate $\gamma_{t}$. Money supply $\left(M_{t}\right)$ is also exogenous and growing stochastically at a rate $\mu_{t}$. Then

$$
y_{t}=\gamma_{t} y_{t-1}, \quad \text { and } \quad M_{t}=\mu_{t} M_{t-1} \text {. }
$$

The rates $\gamma_{t}$ and $\mu_{t}$ are known at the beginning of period $t$.

Let $(\Theta, \mathcal{Z})$ be a measurable space. Uncertainty will be characterized by the shock $\theta_{t}=\left[\gamma_{t}, \mu_{t}\right]^{\prime} \in \Theta$. The set $\Theta$ is assumed to be compact. This shock follows a first-order Markov process with transition probability function $Q: \Theta \times \mathcal{Z} \rightarrow[0,1]$. Several assumptions are made throughout the paper:

Assumption 1. The transition function $Q$ has the Feller property that is $\Gamma$ for any bounded continuous function $f: \Theta \rightarrow R$ The function

$$
(T f)(\theta)=\int_{\Theta} f\left(\theta^{\prime}\right) Q(\theta, d \theta)
$$

is bounded and continuous. The process defined by $Q$ has a stationary distribution $\Gamma$.

Assumption 2. The utility function $u: R_{+} \rightarrow R$ is given by

$$
u(c)=\log (c) .
$$

In order to have a finite value function assume

\section{Assumption 3.}

$$
-\infty<\beta \int_{\Theta} \log \left(\gamma^{\prime}\right) Q\left(\theta, d \theta^{\prime}\right)<\infty, \quad \text { for all } \theta \in \Theta .
$$

Also Ta sufficient assumption to have a monetary equilibrium is 


\section{Assumption 4.}

$$
0<\beta \int_{\Theta}\left(1 / \mu^{\prime}\right) Q\left(\theta, d \theta^{\prime}\right)<1, \quad \text { for all } \theta \in \Theta .
$$

As it was explained above $\Gamma$ given the processes $\left\{P_{t}, i_{t}, H_{t+1}, y_{t}, \bar{B}_{t}^{a}, K_{t}\right\}_{t=0}^{\infty} \Gamma$ the agent's problem is to choose sequences $\left\{c_{t}, M_{t}^{d}, B_{t}^{d}, N_{t}\right\}_{t=0}^{\infty}$ so as to maximize

$$
E_{0}\left[\sum_{t=0}^{\infty} \beta^{t} u\left(c_{t}\right)\right],
$$

subject to the constraints

$$
\begin{gathered}
P_{t} c_{t} \leq N_{t} M_{t}^{d}, \\
N_{t} \geq 1 \\
B_{t}^{d}+M_{t}^{d} \leq W_{t}, \\
W_{t+1}=W_{t}+i_{t}\left(B_{t}^{d}-\frac{N_{t}-1}{2} M_{t}^{d}\right)+H_{t+1}+i_{t} \bar{B}_{t}^{a}+P_{t} y_{t}-P_{t} c_{t}-\left(N_{t}-1\right) K_{t},
\end{gathered}
$$

and the nonnegativity constraints

$$
c_{t} \geq 0 \Gamma M_{t}^{d} \geq 0 \Gamma
$$

where

$$
H_{t+1}=\left(\mu_{t+1}-1\right) M_{t}
$$

From the discussion in Section $2 \Gamma$ it is assumed that each trip to the bank (except for the first one $\Gamma$ which is free) costs a fixed proportion $k \equiv 2 \widetilde{k} \geq 0$ of current income $P_{t} y_{t}{ }^{6}$ Therefore $K_{t}=k P_{t} y_{t}$.

The market-clearing conditions for $t=0,1, \ldots$ are:

$$
\begin{gathered}
c_{t}+\left(N_{t}-1\right) k y_{t}=y_{t}, \\
M_{t}^{d}=M_{t} .
\end{gathered}
$$

Lemma 1. Under Assumptions $1 \Gamma 2 \Gamma$ and 3 for any feasible consumption sequence $\left\{c_{t}\right\}_{t=0}^{\infty} \Gamma$

$$
E_{0}\left[\sum_{t=0}^{\infty} \beta^{t} u\left(c_{t}\right)\right] \leq \bar{u}<\infty .
$$

\footnotetext{
${ }^{6}$ In this representative agent economy, each trip to the bank implies two trips in the economy of the previous section: one by the household and one by the firm.
} 
Proof. See Appendix A.1.

In order to have stationary endogenous variables Tnormalize nominal variables by $M_{t}$ and define $\Gamma$

$$
p_{t}=\frac{P_{t}}{M_{t}}, \quad b_{t}=\frac{B_{t}^{d}}{M_{t}}, \quad m_{t}=\frac{M_{t}^{d}}{M_{t}}, \quad \bar{b}_{t}^{a}=\frac{\bar{B}_{t}^{a}}{M_{t}}, \quad w_{t}=\frac{W_{t}}{M_{t}} .
$$

Assuming $i_{t}>0$ The GCIA constraint (9) will be binding. Then $\Gamma$ using (9) and normalizing variables Tthe agent's problem becomes

$$
\max E_{0}\left[\sum_{t=0}^{\infty} \beta^{t} u\left(c_{t}\right)\right]
$$

subject to

$$
\begin{aligned}
\frac{p_{t} c_{t}}{m_{t}} & \geq 1, \\
b_{t}+m_{t} & \leq w_{t},
\end{aligned}
$$

plus the nonnegativity constraint (13) Гwith

$$
\begin{aligned}
\mu_{t+1} w_{t+1}= & \left(1+i_{t}\right) b_{t}+\left(1+\frac{i_{t}}{2}\right) m_{t}-\left(1+\frac{i_{t}}{2}\right) p_{t} c_{t}+\mu_{t+1}-1+i_{t} \bar{b}_{t}^{a} \\
& +p_{t} y_{t}-\left(\frac{p_{t} c_{t}}{m_{t}}-1\right) k p_{t} y_{t} .
\end{aligned}
$$

\subsubsection{Definition of Equilibrium}

Given the recursive structure of this problem Tequilibrium prices will be expressed as fixed functions of the state of the economy which is summarized by the current levels of output $\Gamma y_{t} \Gamma$ initial wealth $\Gamma w_{t} \Gamma$ and $\operatorname{shocks} \Gamma \theta_{t}$. Then

$$
p_{t}=p\left(y_{t}, w_{t}, \theta_{t}\right) \text { and } \quad i_{t}=i\left(y_{t}, w_{t}, \theta_{t}\right)
$$

Later it will be shown that these functions take the form

$$
p_{t}=p\left(y_{t}, \theta_{t}\right) \text { and } \quad i_{t}=i\left(\theta_{t}\right),
$$

where $p\left(y_{t}, \theta_{t}\right) y_{t}$ is independent of $y_{t}$.

Define $v(y, w, \theta)$ as the agent's lifetime expected utility $\Gamma$ given output $y \Gamma$ initial wealth $w$ Tand the shock $\theta$. By Lemma $1 \Gamma$ this is well defined and finite. 
Given the price functions $p(\cdot)$ and $i(\cdot)$ Tthe value function for the consumer's problem satisfies:

$$
v(y, w, \theta)=\max \left\{u(c)+\beta \int_{\Theta} v\left(y^{\prime}, w^{\prime}, \theta^{\prime}\right) Q\left(\theta, d \theta^{\prime}\right)\right\}
$$

subject to

$$
\begin{gathered}
\frac{p c}{m} \geq 1, \\
b+m \leq w, \\
m \geq 0, c \geq 0,
\end{gathered}
$$

where

$$
\begin{aligned}
w^{\prime}= & \frac{1}{\mu^{\prime}}\left[(1+i) b+\left(1+\frac{i}{2}\right) m-\left(1+\frac{i}{2}\right) p c+\mu^{\prime}-1+i \bar{b}^{a}\right. \\
& \left.+p y-\left(\frac{p c}{m}-1\right) k p y\right] .
\end{aligned}
$$

Let $\mathcal{W}=[0, \bar{w}]$ with $0<\bar{w}<\infty$ so that $w_{t} \in \mathcal{W}$ all $t$. Let $\mathcal{S} \equiv R_{+} \times \mathcal{W} \times \Theta$ with $s$ being a generic element of $\mathcal{S}$. The following definition describes the concept of equilibrium used here.

Definition 1. A recursive competitive equilibrium is a set of price functions $p: \mathcal{S} \rightarrow R_{++}$and $i: \mathcal{S} \rightarrow R_{++}$Tallocation functions $c: \mathcal{S} \rightarrow R_{+} \Gamma$ $b: \mathcal{S} \rightarrow R$ Tand $m: \mathcal{S} \rightarrow R_{+}$and a value function $v: \mathcal{S} \rightarrow R$ such that $\Gamma$ for all $s \in \mathcal{S}$

1. given $p(s)$ and $i(s) \Gamma v(s)$ solves the consumer's problem $\Gamma$ and

2. markets clear $\Gamma$ that is $\Gamma$

$$
\begin{gathered}
y=c(s)+\left[\frac{p(s) c(s)}{m(s)}-1\right] k y, \\
m(s)=1, \\
b(s)=0,
\end{gathered}
$$

where $c(s) \Gamma m(s)$ and $b(s)$ attain $v(s)$. 


\subsubsection{Existence of Equilibrium}

In equilibrium $b_{t}=0$ and $m_{t}=1$. Then define $\mathcal{B}=[-b, b]$ with $0<b<\infty \Gamma$ and $\mathcal{M}=[0, \bar{m}]$ with $\bar{m}>1 \Gamma$ such that $b_{t} \in \mathcal{B} \Gamma m_{t} \in \mathcal{M}$ all $t$. Also in equilibrium $0 \leq c_{t} \leq y_{t}$. Let the operator $T$ be

$$
(T v)(s)=\max \left\{u(c)+\beta \int_{\Theta} v\left(s^{\prime}\right) Q\left(\theta, d \theta^{\prime}\right)\right\},
$$

over $c \Gamma m \Gamma$ and $b$ subject to $(20) \Gamma(21) \Gamma(23) \Gamma$ and

$$
m \in \mathcal{M} \quad b \in \mathcal{B} \quad 0 \leq c \leq y .
$$

Define $\mathcal{V}(\mathcal{S})$ as the space of functions $f: \mathcal{S} \rightarrow R$ that are jointly continuous and bounded in the sup norm.

Proposition 2. Under Assumptions 1Г2Гand 3Гand given the functions $p(s)$ and $i(s)$ there exists a unique solution $v^{*}: \mathcal{S} \rightarrow R$ to the consumer's problem.

Proof. See Appendix A.3.

The next proposition characterizes the value function $v^{*}(s)$.

Proposition 3. Under Assumptions $1 \Gamma 2 \Gamma$ and $3 \Gamma v^{*}(s)$ is an increasing $\Gamma$ concave $\Gamma$ continuously differentiable function of $w$ for each $(y, \theta)$.

Proof. See Appendix A.4.

The first order conditions (FOCs) of this problem are (assuming $i_{t}>0$ )

$$
\begin{gathered}
\frac{u^{\prime}(c)}{p}+\frac{\lambda}{m}=\beta\left[1+\frac{i}{2}+\frac{k p y}{m}\right] \int_{\Theta}\left(\frac{1}{\mu^{\prime}}\right) v_{w}\left(s^{\prime}\right) Q\left(\theta, d \theta^{\prime}\right), \\
\delta+\frac{\lambda p c}{m^{2}}=\beta\left[1+\frac{p c}{m^{2}} k p y+\frac{i}{2}\right] \int_{\Theta}\left(\frac{1}{\mu^{\prime}}\right) v_{w}\left(s^{\prime}\right) Q\left(\theta, d \theta^{\prime}\right), \\
\delta=\beta(1+i) \int_{\Theta}\left(\frac{1}{\mu^{\prime}}\right) v_{w}\left(s^{\prime}\right) Q\left(\theta, d \theta^{\prime}\right), \\
\left(\frac{p c}{m}-1\right) \lambda=0 \quad ; \quad \lambda \geq 0,
\end{gathered}
$$

plus the constraints (21) and (23) where $\lambda$ and $\delta$ are the Lagrange multipliers associated with (20) and (21) Гrespectively. For notational simplicity $\Gamma e x p l i c i t$ reference to the dependence on $s$ of the pricing and allocation functions 
has been suppressed. These conditions have the usual interpretations. For example the left-hand side of (25) is the total marginal utility derived from an increase in consumption measured in scaled currency units. The first element is the direct increase in the utility function. Also $\Gamma$ an increase in consumption relaxes constraint (20). The second element refers to the value of this effect. The right-hand side includes the marginal costs associated with increasing consumption. Since money has to be used to consume Tthese costs include the foregone interest from the reduction of the average bond holdings plus the transaction costs of new trips to the bank. The rest of conditions have similar interpretations. Additionally Texpressions (25) and (26) yield

$$
\frac{u^{\prime}(c)}{p}=\delta+\beta \frac{k p y}{m}\left(1-N^{h}\right) \int_{\Theta}\left(\frac{1}{\mu^{\prime}}\right) v_{w}\left(s^{\prime}\right) Q\left(\theta, d \theta^{\prime}\right) .
$$

When the constraint (20) is binding and $N_{t}^{h}=1 \Gamma$ the model behaves as a standard CIA model and the marginal utility of consumption is equal to the marginal utility of wealth. However $\Gamma$ when that constraint is not binding and $N_{t}^{h}>1$ The marginal utility of consumption is larger than the marginal utility of wealth. This is because in this case not all increases in income can be transferred to increases in consumption since a proportion is lost in transaction costs.

Remark. For the case where $N>1$ (so that $\lambda=0$ ) $\Gamma$ the Baumol's square-root formula

$$
\frac{M^{d}}{P}=\sqrt{\frac{2 c k y}{i}}
$$

can be obtained from (26) and (27).

The envelope condition is

$$
v_{w}(s)=\delta(s)
$$

The market clearing conditions are

$$
m(s)=1
$$

$\operatorname{and}^{7}$

$$
y=c(s)+\left[\frac{p(s) c(s)}{m(s)}-1\right] k y .
$$

\footnotetext{
${ }^{7}$ Walras's Law implies that the third market clearing condition is also satisfied.
} 
Conditions (25) to (32) plus constraints (21) and (23) form a system of nine equations in nine unknown functions of $s$. These unknown functions are two prices $\Gamma p$ and $i \Gamma$ three allocations $\Gamma c \Gamma b \Gamma$ and $m \Gamma$ two multipliers $\Gamma \lambda$ and $\delta$ Гnext period's wealth $\Gamma w^{\prime} \Gamma$ and the value function $\Gamma v_{w}$. Furthermore $\Gamma$ for a given function $p(s)$ Tthe condition for equilibrium in the product market may be rewritten as

$$
c(s)=\frac{(1+k) y}{1+k p(s) y} \equiv c[p(s) ; y] .
$$

Assumption 2 plus (33) and (28) imply that (25) and (26) take the form

$$
\frac{1+k p(s) y}{(1+k) p(s) y}=\beta\left[1+k p(s) y+k \frac{(1+k) p(s)^{2} y^{2}}{1+k p(s) y}\right] \int_{\Theta}\left(\frac{\delta\left(s^{\prime}\right)}{\mu^{\prime}}\right) Q\left(\theta, d \theta^{\prime}\right)-2 \lambda(s)
$$

and

$$
\delta(s)=\beta\left[1+2 k \frac{(1+k) p(s)^{2} y^{2}}{1+k p(s) y}\right] \int_{\Theta}\left(\frac{\delta\left(s^{\prime}\right)}{\mu^{\prime}}\right) Q\left(\theta, d \theta^{\prime}\right)-2 \lambda(s),
$$

respectively. From (26) $\Gamma$

$$
i(s)=2\left[k \frac{(1+k) p(s)^{2} y^{2}}{1+k p(s) y}-\frac{\lambda(s)}{\beta \int_{\Theta}\left(\delta\left(s^{\prime}\right) / \mu^{\prime}\right) Q\left(\theta, d \theta^{\prime}\right)}\right] .
$$

At the same time $\Gamma$ for condition (20) to be satisfied it must be the case that $p(s) c[p(s) ; y] \geq 1 \Gamma$ or $\Gamma$ by using $(33) \Gamma p(s) y \geq 1$. Notice that all these conditions depend on $p(s)$ through the product $p(s) y \Gamma$ which can be interpreted as the income velocity of money. Also notice that the only variable from the state vector $s$ that appears in these expressions is $\theta \Gamma$ which means that the equilibrium functions will only depend on this variable. Therefore $\Gamma$ defining $v(\theta) \equiv p(\theta) y \Gamma$ the equilibrium conditions may be rewritten as the following system

$$
\begin{gathered}
\Psi[v(\theta)]=\beta \Omega[v(\theta)] \int_{\Theta}\left(\frac{\delta\left(\theta^{\prime}\right)}{\mu^{\prime}}\right) Q\left(\theta, d \theta^{\prime}\right)-2 \lambda(\theta), \\
\delta\left(\theta^{\prime}\right)=\beta \Phi[v(\theta)] \int_{\Theta}\left(\frac{\delta\left(\theta^{\prime}\right)}{\mu^{\prime}}\right) Q\left(\theta, d \theta^{\prime}\right)-2 \lambda(\theta)
\end{gathered}
$$

and

$$
[v(\theta)-1] \lambda(\theta)=0 ; \quad \lambda(\theta) \geq 0,
$$


with

$$
\begin{gathered}
\Psi(x)=\frac{1+k x}{(1+k) x}, \\
\Omega(x)=1+k x+k \frac{(1+k) x^{2}}{1+k x},
\end{gathered}
$$

and

$$
\Phi(x)=1+2 k \frac{(1+k) x^{2}}{1+k x}
$$

where

$$
\lim _{x \rightarrow 0} \Psi(x)=+\infty, \quad \lim _{x \rightarrow \infty} \Psi(x)=\delta_{k}, \quad \Psi(1)=1, \quad \Psi^{\prime}(x)<0,
$$

with

$$
\begin{gathered}
\delta_{k}=\frac{k}{1+k}>0, \quad \text { for } k>0 \\
\lim _{x \rightarrow 0} \Omega(x)=1, \quad \lim _{x \rightarrow \infty} \Omega(x)=+\infty, \quad \Omega(1)=1+2 k, \quad \Omega^{\prime}(x)>0,
\end{gathered}
$$

and

$$
\lim _{x \rightarrow 0} \Phi(x)=1, \quad \lim _{x \rightarrow \infty} \Phi(x)=+\infty, \quad \Phi(1)=1+2 k, \quad \Phi^{\prime}(x)>0 .
$$

The solution of this system of equations (35)-(37) is characterized by three functions of $\theta \Gamma$

$$
\begin{aligned}
& \delta: \quad \Theta \rightarrow \mathcal{D} \in R_{+}, \\
& v: \quad \Theta \rightarrow \mathcal{P} \in R_{+}, \\
& \lambda: \quad \Theta \rightarrow \mathcal{L} \in R_{+} .
\end{aligned}
$$

These results confirm the conjecture made in (18) about the supports for the price functions $p(\cdot)$ and $i(\cdot)$.

In order to prove existence and uniqueness of a competitive equilibrium I will use a reformulation of Proposition 17.5 in Stokey and Lucas [28]. A key step in applying this theorem is the construction of suitable sets $\mathcal{D} \Gamma \mathcal{P}$ and $\mathcal{L}$. For a given function $\delta(\theta)$ define

$$
L[\delta(\theta) ; \theta] \equiv \int_{\Theta}\left(\frac{\delta\left(\theta^{\prime}\right)}{\mu^{\prime}}\right) Q\left(\theta, d \theta^{\prime}\right)
$$


Then (35) and (37) determine uniquely values for $v$ and $\lambda$ as a function of $\delta(\theta)$ and $\theta$ in the following way. Define $\hat{v}[\delta(\theta) ; \theta]$ as the value of $v$ such that

$$
\Psi(\widehat{v})=\beta \Omega(\widehat{v}) L[\delta(\theta) ; \theta]
$$

Because of the properties of the functions $\Psi(\cdot)$ and $\Omega(\cdot)$ There exists only one value of $v$ that satisfies (39). Also define $\hat{\Theta}$ as

$$
\widehat{\Theta}=\{\theta \in \Theta: \widehat{v}[\delta(\theta) ; \theta] \geq 1\},
$$

orTfrom (35) $\Gamma$

$$
\widehat{\Theta}=\{\theta \in \Theta: 1 \geq \beta(1+2 k) L[\delta(\theta) ; \theta]\} .
$$

Then define the functions $v[\delta(\theta) ; \theta]$ and $\lambda[\delta(\theta) ; \theta]$ as

$$
v[\delta(\theta) ; \theta]= \begin{cases}\hat{v}[\delta(\theta) ; \theta] & \text { for } \theta \in \widehat{\Theta} \\ 1 & \text { for } \theta \in \widehat{\Theta}^{c}\end{cases}
$$

and

$$
\lambda[\delta(\theta) ; \theta]= \begin{cases}0 & \text { for } \theta \in \hat{\Theta} \\ \frac{1}{2}\{\beta(1+2 k) L[\delta(\theta) ; \theta]-1\} & \text { for } \theta \in \widehat{\Theta}^{c}\end{cases}
$$

The function $\delta(\theta)$ is then determined from (36)

$$
\delta(\theta)=\beta \Phi[v(\delta(\theta) ; \theta)] L[\delta(\theta) ; \theta]-\lambda[\delta(\theta) ; \theta] .
$$

It is clear that if $\delta(\theta)$ is a continuous function of $\theta$ so will $v[\delta(\theta) ; \theta]$ and $\lambda[\delta(\theta) ; \theta]$ be. From $(41)$ and $(42) \Gamma$

$$
\begin{aligned}
& \mathcal{P}=[1,+\infty) \\
& \mathcal{L}=[0,+\infty)
\end{aligned}
$$

On the other hand

$$
\mathcal{D}=\left[\delta_{k}, 1\right]
$$


with $\psi_{k}$ defined in $(38)$

$$
\delta_{k}=\frac{k}{1+k} .
$$

This is done in Appendix B.

Let $F$ be the space of continuous functions

$$
f: \Theta \rightarrow\left[\delta_{k}, 1\right]
$$

An equilibrium can be found as a fixed point of the operator $T: F \rightarrow F$ defined as

$$
(T f)(\theta)=\int_{\Theta} G\left[\theta, \theta^{\prime}, f\left(\theta^{\prime}\right)\right] Q\left(\theta, d \theta^{\prime}\right),
$$

where

$$
G\left[\theta, \theta^{\prime}, f\left(\theta^{\prime}\right)\right]=\beta \Phi[v(f(\theta) ; \theta)] \frac{f\left(\theta^{\prime}\right)}{\mu^{\prime}}-2 \lambda(f(\theta) ; \theta) .
$$

The formal expression of this statement is included in Proposition 4.

Proposition 4. Under Assumptions 1 Г 2 Г 3 Гand 4 Гthere exists a unique recursive competitive equilibrium to the Lucas Model for all finite $k>0$.

Proof. See Appendix A.5.

\subsubsection{Discussion of the Equilibrium}

Let $\delta^{*}(\theta)$ be the fixed point associated with (45). Also define

$$
v^{*}(\theta) \equiv v\left[\delta^{*}(\theta) ; \theta\right] \quad \text { and } \quad \lambda^{*}(\theta) \equiv \lambda\left[\delta^{*}(\theta) ; \theta\right] .
$$

An immediate result is that the CIA model in Lucas [18] appears as a limiting case of this model.

Proposition 5. There exists a finite $\bar{k}>0$ such that for all $k \geq \bar{k}$ and $\theta \in \Theta$

$$
v^{*}(\theta)=1
$$

Proof. See Appendix A.6.

This result shows that the CIA model is a limiting case of this model since for a $k$ that is high enough the agent will go to the bank just once. It is often said that we can look at CIA models as economies with the following transaction technology. The first trip to the bank is free and the next ones are prohibitively expensive which is what makes the agent go only once to the bank. Proposition 6 states in an objective way what "prohibitively expensive" means. 


\section{A Precautionary Demand for Money}

A precautionary demand for money can be introduced by adopting the timing in Svensson [29]. Throughout the rest of the paper the following model will be referred to as Svensson Model. The physical setup is identical to the one in the previous subsection. The only difference appears in the order in which markets open within the period. It is assumed that the product market opens at the beginning of the period while the asset market opens at the end. When the asset market opens $\Gamma$ the shopper is at the bank in his location. He enters this market with wealth $W_{t}^{h}$. At the bank $\Gamma$ the agent decides on an initial deposit in his account and on the size of the withdrawals to be made the following period. It is assumed that he can only adjust the size of his withdrawals at his bank. Since consumption is only known after the money decision is made $\Gamma$ once next period's state is realized $\Gamma$ the number of trips to the bank needed to finance the agent's consumption stream is a random variable when money holdings are decided. This will imply a precautionary demand for money. Once the state of the economy is realized at the beginning of the following period $\Gamma$ the product market opens and the agent consumes. At the closing of the product market Tinterest rates on average bond holdings and brokerage fees are paid $\Gamma$ the asset market opens again $\Gamma$ and the process starts all over.

\subsection{The Representative Agent Economy}

The same type of arguments used in the previous subsection can be used here to get to the following representative agent economy. Given the processes $\left\{P_{t}, i_{t}, H_{t+1}, y_{t}, \bar{B}_{t}^{a}\right\}_{t=0}^{\infty}$ Tthe agent will choose sequences $\left\{c_{t}, M_{t+1}^{d}, B_{t+1}, N_{t}\right\}_{t=0}^{\infty}$ so as to maximize

$$
E_{0}\left[\sum_{t=0}^{\infty} \beta^{t} u\left(c_{t}\right)\right],
$$

subject to the constraints

$$
\begin{gathered}
P_{t} c_{t} \leq N_{t} M_{t}^{d} \\
N_{t} \geq 1 \\
B_{t+1}^{d}+M_{t+1}^{d} \leq W_{t} \\
W_{t+1}=B_{t+1}^{d}+M_{t+1}^{d}+i_{t}\left(B_{t+1}^{d}-\frac{N_{t+1}-1}{2} M_{t+1}^{d}\right)+H_{t+1}+i_{t} \bar{B}_{t+1}^{a} \\
+P_{t+1} y_{t+1}-P_{t+1} c_{t+1}-\left(N_{t}-1\right) k P_{t+1} y_{t+1}
\end{gathered}
$$


and the nonnegativity constraints

$$
c_{t} \geq 0 \Gamma M_{t+1}^{d} \geq 0 \Gamma
$$

where

$$
H_{t+1}=\left(\mu_{t}-1\right) M_{t} .
$$

The market-clearing conditions for $t=0,1, \ldots$ are $\Gamma$ again:

$$
\begin{gathered}
c_{t}+\left(N_{t}-1\right) k y_{t}=y_{t}, \\
M_{t}^{d}=M_{t} .
\end{gathered}
$$

Lemma 1 still applies Tand after normalizing nominal variables by $M_{t}$ Tthe agent's problem becomes maximizing the objective function

$$
E_{0}\left[\sum_{t=0}^{\infty} \beta^{t} u\left(c_{t}\right)\right],
$$

over $\left\{m_{t+1}, b_{t+1}, c_{t}, N_{t}\right\}_{t=0}^{\infty}$ subject to the constraints

$$
\begin{gathered}
p_{t} c_{t} \leq N_{t} m_{t}, \\
N_{t} \geq 1, \\
\mu_{t} b_{t+1}+\mu_{t} m_{t+1} \leq w_{t},
\end{gathered}
$$

plus the nonnegativity constraint (51) Гwith

$$
\begin{aligned}
w_{t+1}= & b_{t+1}+m_{t+1}+i_{t}\left(b_{t+1}-\frac{N_{t+1}-1}{2} m_{t+1}\right)+\mu_{t}-1+i_{t} \bar{b}_{t+1}^{a} \\
& +p_{t+1} y_{t+1}-p_{t+1} c_{t+1}-\left(N_{t+1}-1\right) k p_{t+1} y_{t+1},
\end{aligned}
$$

Notice that the constraint (54) does not need to bind for some states as in Svensson [29]. In that case The number of trips to the bank is one although not all money holdings are spent $\Gamma$ i.e.

$$
\begin{gathered}
N_{t}=1, \\
p_{t} c_{t}<N_{t} m_{t} .
\end{gathered}
$$

For other states of the world the agent spends all cash but goes only once to the bank Ti.e.

$$
N_{t}=1
$$




$$
p_{t} c_{t}=N_{t} m_{t} .
$$

Finally there will be cases where the agent will decide to withdraw money several times. If the interest rate is positive it is clear that he will exhaust all cash holdings $\Gamma$ i.e.

$$
\begin{gathered}
N_{t}>1, \\
p_{t} c_{t}=N_{t} m_{t} .
\end{gathered}
$$

\subsubsection{Definition of Equilibrium}

As beforeTthe price functions take the form

$$
p_{t}=p\left(y_{t}, \theta_{t}\right) \text { and } \quad i_{t}=i\left(\theta_{t}\right)
$$

where $p\left(y_{t}, \theta_{t}\right) y_{t}$ is independent of $y_{t}$.

Define $v(y, w, \theta)$ as the agent's lifetime expected utility before the asset market opens and after interest rates and brokerage fees are paid for the current period $\Gamma$ given output $y$ Twealth $w$ Tand the shock $\theta$. By Lemma $1 \Gamma$ this is well defined and finite. Given the price functions $p(\cdot)$ and $i(\cdot) \Gamma$ the value function for the consumer's problem satisfies:

$$
v(y, w, \theta)=\max \left\{u(c)+\beta \int_{\Theta} v\left(y^{\prime}, w^{\prime}, \theta^{\prime}\right) Q\left(\theta, d \theta^{\prime}\right)\right\},
$$

over $m^{\prime} \Gamma b^{\prime} \Gamma c$ and $N \Gamma$ subject to

$$
\begin{gathered}
p c \leq N m, \\
N \geq 1, \\
\mu b^{\prime}+\mu m^{\prime} \leq w,
\end{gathered}
$$

plus the nonnegativity constraint (51) Гwith

$$
\begin{aligned}
w^{\prime}= & b^{\prime}+m^{\prime}+i\left(b^{\prime}-\frac{N^{\prime}-1}{2} m^{\prime}\right)+\mu-1+i \bar{b}^{a \prime}+p^{\prime} y^{\prime} \\
& -p^{\prime} c^{\prime}-\left(N^{\prime}-1\right) k p^{\prime} y^{\prime}
\end{aligned}
$$

Then Definition 1 still represents the equilibrium concept used for this model where the value function is given by $(58)$. 


\subsubsection{Existence of Equilibrium}

It is easy to show that Propositions 1 and 2 still apply. The first order conditions (FOCs) of this problem are (assuming $i_{t}>0$ )

$$
\begin{gathered}
\frac{u^{\prime}(c)}{p}=\delta+\gamma, \\
\gamma m+\lambda=\delta\left(m \frac{i^{\circ}}{2}+k p y\right) \\
\delta=\frac{\beta}{\mu} \int_{\Theta} \gamma^{\prime} N^{\prime} Q\left(\theta, d \theta^{\prime}\right)+\frac{\beta}{\mu} \int_{\Theta} v_{w}\left(s^{\prime}\right)\left(1-\frac{N^{\prime}-1}{2} i\right) Q\left(\theta, d \theta^{\prime}\right), \\
\delta=\frac{\beta}{\mu}(1+i) \int_{\Theta} v_{w}\left(s^{\prime}\right) Q\left(\theta, d \theta^{\prime}\right), \\
(p c-N m) \gamma=0 \quad ; \quad \gamma \geq 0, \\
(n-1) \lambda=0 ; \quad \lambda \geq 0,
\end{gathered}
$$

plus the constraints $(61)$ and (62) where $\gamma \Gamma \lambda$ and $\delta$ are the Lagrange multipliers associated with $(59) \Gamma(60)$ and $(62) \Gamma$ respectively and $i^{\circ}$ refers to the interest rate determined the previous period. For notational simplicity

plicit reference to the dependence on $s$ of the pricing and allocation functions has been suppressed.

The envelope condition is

$$
v_{w}(s)=\delta(s)
$$

The market clearing conditions are

$$
m(s)=1
$$

and

$$
y=c(s)+[N(s)-1] k y .
$$

As before $\Gamma$ conditions (63) to (71) plus constraints (61) and (62) form a system of eleven equations in eleven unknown functions of $\theta$. These unknown functions are two prices $\Gamma p$ and $i \Gamma$ three allocations $\Gamma c \Gamma b^{\prime} \Gamma$ and $m^{\prime} \Gamma$ velocity of money $N \Gamma$ three multipliers $\Gamma \gamma \Gamma \lambda$ and $\delta \Gamma$ next period's wealth $\Gamma w^{\prime} \Gamma$ and the value function $\Gamma v_{w}$. Furthermore $\Gamma$ for a given function $N(\theta) \Gamma$ the condition for equilibrium in the product market may be rewritten as

$$
c(\theta)=[1-(N(\theta)-1)] y \equiv c[N(\theta) ; y]
$$


Also $\Gamma$ conditions $(64) \Gamma(65)$ and $(66)$ can be used to get a demand for money with a Baumol flavor to it. Assuming that $p\left(\theta^{\prime}\right) c\left(\theta^{\prime}\right)=N\left(\theta^{\prime}\right) m\left(\theta^{\prime}\right) \Gamma$ so that $\lambda\left(\theta^{\prime}\right)=0 \Gamma$ for all $\theta^{\prime} \in \Theta \Gamma(64) \Gamma(65)$ and $(66)$ yield

$$
\frac{i(\theta)}{2} \int_{\Theta} \delta\left(\theta^{\prime}\right) Q\left(\theta, d \theta^{\prime}\right)=\frac{p\left(\theta^{\prime}\right) c\left(\theta^{\prime}\right)}{m\left(\theta^{\prime}\right)^{2}} k p\left(\theta^{\prime}\right) y\left(\theta^{\prime}\right) \delta\left(\theta^{\prime}\right) Q\left(\theta, d \theta^{\prime}\right)
$$

or $\Gamma$

$$
\int_{\Theta}\left(\frac{i(\theta)}{2}-\frac{p\left(\theta^{\prime}\right) c\left(\theta^{\prime}\right)}{m\left(\theta^{\prime}\right)^{2}} k p\left(\theta^{\prime}\right) y\left(\theta^{\prime}\right)\right) \delta\left(\theta^{\prime}\right) Q\left(\theta, d \theta^{\prime}\right)=0 .
$$

This expression determines a precautionary demand for money. The agent would like to balance $\Gamma$ in every state of nature $\Gamma$ the marginal opportunity cost of demanding an additional unit of currency equal to the left side of (73) Гwith its marginal transaction cost Tequal to the right side of (73). Since this is not possible when the asset market opens $\Gamma$ the agent will determine money holdings to balance the expected costs using the marginal utility of wealth $\Gamma \delta\left(\theta^{\prime}\right) \Gamma$ as weights for each state of nature. In general the problem will be more complicated since the agent will also consider the possibility of states of nature where $p\left(\theta^{\prime}\right) c\left(\theta^{\prime}\right)<N\left(\theta^{\prime}\right) m\left(\theta^{\prime}\right)$. The type of arguments in Baumol [2] or Tobin [30] does not appear in those cases 5 however.

Using (72) Гand Assumption 2 and defining $v(\theta) \equiv p(\theta) y(\theta)$ the problem reduces to

$$
\begin{gathered}
\frac{1}{[1-(N(\theta)-1)] v(\theta)}=\delta(\theta)+\gamma(\theta) \\
\gamma(\theta)+\lambda(\theta)=\delta(\theta)\left[k v(\theta)+\frac{i\left(\theta^{\circ}\right)}{2}\right] \\
{[(1-(N(\theta)-1)) v(\theta)-N(\theta)] \gamma(\theta)=0 ; \quad \gamma(\theta) \geq 0,} \\
{[N(\theta)-1] \lambda(\theta)=0 ; \lambda(\theta) \geq 0,} \\
i(\theta)=2 \frac{\int_{\Theta}\left[k \delta\left(\theta^{\prime}\right) v\left(\theta^{\prime}\right) N\left(\theta^{\prime}\right)-\lambda\left(\theta^{\prime}\right)\right] Q\left(\theta, d \theta^{\prime}\right)}{\int_{\Theta} \delta\left(\theta^{\prime}\right) Q\left(\theta, d \theta^{\prime}\right)} .
\end{gathered}
$$

and

$$
\delta(\theta)=\frac{\beta}{\mu} \int_{\Theta}\left[\delta\left(\theta^{\prime}\right)\left(1+2 k v\left(\theta^{\prime}\right) N\left(\theta^{\prime}\right)\right)-2 \lambda\left(\theta^{\prime}\right)\right] Q\left(\theta, d \theta^{\prime}\right),
$$

For a given function $\delta(\theta) \Gamma$ conditions (74)-(78) give unique functions $v(\theta) \equiv v[\delta(\theta) ; \theta] \Gamma N(\theta) \equiv N[\delta(\theta) ; \theta] \Gamma i(\theta) \equiv i[\delta(\theta) ; \theta] \Gamma \gamma(\theta) \equiv \gamma[\delta(\theta) ; \theta] \Gamma$ and $\lambda(\theta) \equiv \lambda[\delta(\theta) ; \theta]$. In order to prove existence and uniqueness of equilibrium I need to show only that there exists a unique solution $\delta(\theta)$ to $(79)$. This 
is done in the next proposition which is just a reformulation of Proposition 4 .

Proposition 6. Under Assumptions 1 Г 2 Г 3 Гand 4 Гthere exists a unique recursive competitive equilibrium to the Svensson Model for all finite $k>0$.

Proof. See Appendix A.7.

\subsubsection{Discussion of the Equilibrium}

As in Svensson [29] the state space $\Theta$ can be divided into two subsets. In the first one the constraint (54) is not binding. Denote this subset as $\Theta_{1}$. For all $\theta \in \Theta_{1}$ Tthen

$$
\lambda(\theta)>0, \quad N(\theta)=1,
$$

so $p(\theta) c(\theta)=v(\theta)$ Tand

$$
\gamma(\theta)=0, \quad p(\theta) c(\theta)<N(\theta) .
$$

In the other region the constraint (54) is binding. However $\Gamma$ in the present model there are two possibilities depending on whether the constraint (55) binds or not. Then $\Gamma$ as in Svensson [29] $\Gamma$ there will be a subset $\Gamma$ call it $\Theta_{2} \Gamma$ where the constraint (55) is binding Ti.e.

$$
\lambda(\theta)>0, \quad N(\theta)=1
$$

so still $p(\theta) c(\theta)=v(\theta)$ Tand

$$
\gamma(\theta)>0, \quad p(\theta) c(\theta)=N(\theta) \Gamma
$$

but also another one $\Gamma \Theta_{3} \Gamma$ where constraint (55) is not binding $\Gamma$ i.e.

$$
\lambda(\theta)=0, \quad N(\theta)>1,
$$

so $p(\theta) c(\theta)<v(\theta)$ Гand

$$
\gamma(\theta)>0, \quad p(\theta) c(\theta)=N(\theta) .
$$

Let $\delta^{*}(\theta)$ be the fixed point associated with (79). Also define

$$
N^{*}(\theta) \equiv N\left[\delta^{*}(\theta) ; \theta\right] \text {. }
$$

The next proposition shows that the CIA model in Svensson [29] appears as a limiting case of this model.

Proposition 7. There exists a finite $\bar{k}>0$ such that for all $k \geq \bar{k}$ and $\theta \in \Theta$

$$
N^{*}(\theta)=1 .
$$

Proof. See Appendix A.8. 


\section{Empirical Results}

\subsection{Data}

For the empirical application of the models quarterly and annual data from 1959 to 1996 on income inflation $\Gamma$ interest rates and money stock from the Citibase database were used. The definition of money used here is M2. The reason for this choice will be explained later. Appendix $\mathrm{C}$ includes information about these series.

First Tthe stationarity of the variables of interest is tested. These variables are output and money growth $\left(\gamma_{t}\right.$ and $\mu_{t}$ Trespectively) income velocity of money $\left(v_{t}\right)$ Cinflation $\left(\pi_{t}\right)$ and nominal interest rate $\left(i_{t}\right) .{ }^{8}$ It has been argued elsewhere ${ }^{9}$ that some of these series may display time trends. In particular $\Gamma$ Marshall [23] finds that time trends are statistically significant for the money growth rate money velocity nominal interest rate and inflation when using quarterly data and M1 as the definition of money. In order to test for the existence of time trends as well as unit roots $\Gamma$ the following equation is fitted by maximum likelihood to each series:

$$
x_{t}=\alpha_{0}+\alpha_{1} t+\alpha_{2} x_{t-1}+u_{t}
$$

for $x_{t}=\gamma_{t} \Gamma \mu_{t} \Gamma v_{t} \Gamma \pi_{t}$ and $i_{t}$. Tables 1 and 2 show Augmented Dickey-Fuller tests based on the $t$-statistic on the hypothesis $\alpha_{2}=1$ against the alternative $\alpha_{2} \neq 1$ for annual and quarterly data Trespectively. The Wald-F test on the joint hypothesis $\alpha_{1}=0$ and $\alpha_{2}=1$ against the alternative $H_{A}: \alpha_{1} \neq 0$ or $\alpha_{2} \neq 1$ is also included.

As Tables 1 and 2 show Tboth hypotheses are rejected for the growth rate of real output at a $5 \%$ significance level. The same conclusions are reached for the growth rate of money at a $10 \%$ significance level for annual data and $5 \%$ level for quarterly data. The null hypothesis that the series follow a stationary process around a linear trend is also rejected on the basis of

\footnotetext{
${ }^{8}$ Income velocity of money is defined as the money stock divided by nominal income. Also, from the models, inflation at time $t$ is equal to

$$
\pi_{t} \equiv \frac{P_{t}}{P_{t-1}}=\frac{\mu_{t}}{\gamma_{t}} \frac{v_{t}}{v_{t-1}}
$$

Because of the assumed stationarity of the processes $\left\{\mu_{t}, \gamma_{t}\right\}_{t=0}^{\infty}$, the process $\left\{\pi_{t}\right\}_{t=0}^{\infty}$ should be stationary as well.

${ }^{9}$ See Marshall [23] and Stock and Watson [27].
} 
the t-statistics on the coefficient $\alpha_{1} \cdot{ }^{10}$ Thus Tit seems that the growth rates of real output and of the money stock follow stationary processes. This is important because these are the state variables in the model and are assumed to be stationary. HoweverTalthough the model also predicts the rest of the variables to be stationary $\Gamma$ this does not show in the data since the tests cannot reject the presence of unit roots in the time series. It is interesting though that $\Gamma$ unlike the papers mentioned above $\Gamma$ the Augmented DickeyFuller test rejects the existence of time trends for all series but the velocity of money.

For the empirical applications of the model $\Gamma$ I will maintain the model's result that all variables are stationary indicate so for some of them. One possibility is to think that they follow stationary processes but the small sample implies that the statistics do not have enough power to reject the null hypothesis of nonstationarity when it is not true. Of course this assumption is not very appealing for the case of the interest rates but it does not seem too unrealistic for the rest of the variables.

It is for this reason that M2 is the definition of money used in this paper. Besides having a very small upward trend $Г \mathrm{M} 2$ has been more stable than M1 which has had a pronounced upward trend until the early $80 \mathrm{~s}$. M2Гtherefore $\Gamma$ seems closer to the assumption of stationarity.

\subsection{Solution Method}

Although neither of these models can be solved analytically their solution can be approximated by using the Parameterized Expectations Algorithm (PEA) explained in Marcet [22]. The way the PEA solution method works is by approximating the integrals in (36) and (79) with a particular function $\eta(\theta ; \xi)$ where $\xi$ is a certain vector of parameters. For the Lucas Model this function takes the form $\Gamma$

$$
\begin{aligned}
L\left[\delta^{*}(\theta) ; \theta\right]= & \int_{\Theta}\left(\frac{\delta^{*}\left(\theta^{\prime}\right)}{\mu^{\prime}}\right) Q\left(\theta, d \theta^{\prime}\right) \simeq \eta(\theta ; a) \\
= & a_{1} \exp \left[a_{2} \ln (\mu)+a_{3} \ln (\gamma)+a_{4} \ln (\mu)^{2}+a_{5} \ln (\gamma)^{2}\right. \\
& \left.\quad+a_{6} \ln (\mu) \ln (\gamma)\right] .
\end{aligned}
$$

\footnotetext{
${ }^{10}$ In addition, the hypothesis of a unit root is rejected in the constrained model with $\alpha_{1}=0$ for both of the series at a $5 \%$ significance level.
} 
For the Svensson model Tthe integral was decomposed in two terms

$$
\begin{aligned}
S\left[\delta^{*}(\theta) ; \theta\right] & =\int_{\Theta}\left[\delta\left(\theta^{\prime}\right)\left(1+2 k v\left(\theta^{\prime}\right) N\left(\theta^{\prime}\right)\right)-2 \lambda\left(\theta^{\prime}\right)\right] Q\left(\theta, d \theta^{\prime}\right) \\
& =S^{1}\left[\delta^{*}(\theta) ; \theta\right]+2 S^{2}\left[\delta^{*}(\theta) ; \theta\right]
\end{aligned}
$$

and then approximated with two functions

$$
\begin{aligned}
S^{1}\left[\delta^{*}(\theta) ; \theta\right]= & \int_{\Theta} \delta\left(\theta^{\prime}\right) Q\left(\theta, d \theta^{\prime}\right) \simeq \eta\left(\theta ; b^{1}\right)=b_{1}^{1}\left[\exp b_{2}^{1} \ln (\mu)\right. \\
& \left.+b_{3}^{1} \ln (\gamma)+b_{4}^{1} \ln (\mu)^{2}+b_{5}^{1} \ln (\gamma)^{2}+b_{6}^{1} \ln (\mu) \ln (\gamma)\right]
\end{aligned}
$$

and $\Gamma$

$$
\begin{aligned}
S^{2}\left[\delta^{*}(\theta) ; \theta\right]= & \int_{\Theta}\left[\delta\left(\theta^{\prime}\right) k v\left(\theta^{\prime}\right) N\left(\theta^{\prime}\right)-\lambda\left(\theta^{\prime}\right)\right] Q\left(\theta, d \theta^{\prime}\right) \simeq \eta\left(\theta ; b^{2}\right) \\
= & b_{1}^{2}\left[\exp b_{2}^{2} \ln (\mu)+b_{3}^{2} \ln (\gamma)+b_{4}^{2} \ln (\mu)^{2}+b_{5}^{2} \ln (\gamma)^{2}\right. \\
& \left.+b_{6}^{2} \ln (\mu) \ln (\gamma)\right] .
\end{aligned}
$$

In order to use the PEA solution method Tfirst a time series is simulated for the exogenous process $\left\{\theta_{t}\right\}$. Then $\Gamma$ with an initial value for the parameter vector $\xi$ say $\xi^{0}$ Tthe model can be solved and a time series for the endogenous processes can be generated. For any given value of $\xi^{0} \Gamma$ a new value $\xi^{1}$ can be found by running a nonlinear regression either of

$$
\frac{\delta_{t+1}}{\mu_{t+1}}
$$

or

$$
\delta_{t+1}\left[1+2 k v_{t+1} N_{t+1}\right]-2 \lambda_{t+1},
$$

on the space of functions generated by $\eta\left(\theta_{t} ; \xi\right)$. The standard implementation of the PEA finds the best approximation $\eta\left(\theta ; \xi^{*}\right)$ by iterating on this process.

In order to simulate the exogenous process $\left\{\theta_{t}\right\} \Gamma$ a $\operatorname{VAR}(1)$ is fitted to data on real output and money growth rates. The results of this estimation appear in Tables 3 and 4. Also Tlikelihood ratio tests on the degree of the VAR were conducted. These tests accept $\Gamma$ at a $5 \%$ significance level $\Gamma$ the $\operatorname{VAR}(1)$ over other specifications.

Tables 5 and 6 contain the estimated values for the vectors $a \Gamma b^{1}$ and $b^{2}$. All the simulations were done for $\beta=0.99$ and $k=0.0116$ with annual data and for $\beta=0.9975$ and $k=0.0028$ with quarterly data. These values 
were chosen to get a reasonable approximation to the sample moments in the following subsection. The transaction cost parameter is in accordance with other estimations for the U.S. economy. ${ }^{11}$ Since this solution procedure is just an approximation of the true rational expectations equilibrium $\Gamma$ the accuracy test described in Den Haan and Marcet [7] is used to check on how close this approximation is to the solution of the model. This procedure tests the hypothesis of the errors from the Euler equation (36) or (79) being orthogonal to the current information set. The results of this test are included in Tables 7 and 8. Since the percentages of times the test statistic is in the critical regions are very close to the theoretical $5 \%$ Tthe approximation seems accurate.

\subsection{The Volatility of Money Velocity}

As it is shown in Propositions 5 and $7 \Gamma$ conventional CIA models may be considered particular cases of these models when the parameter $k \Gamma$ the proportional cost of going to the bank $\Gamma$ is large enough. If this is the case $\Gamma$ it would be prohibitively expensive to make more than one withdrawal. For small $\Gamma$ and more realistic $\Gamma$ values of $k$ Tthe Baumol's inventory-theoretic considerations that are responsible for variations in money velocity in response to endogenous changes in the interest rate will appear here too. Therefore $\Gamma$ these models have the potential to explain some of the volatility that other models cannot account for. The experiment to be performed in this section is to see whether the models in this paper can generate statistics consistent with sample moments computed from U.S. data.

Tables 9 to 12 report the statistics included in this paper for both annual and quarterly data. These statistics are $\Gamma$ the means and standard deviations (Tables 9 and 11) as well as the correlation coefficients (Tables 10 and 12) of $\gamma_{t} \Gamma \mu_{t} \Gamma v_{t} \Gamma \pi_{t}$ and $i_{t}$. The column labelled Lucas includes the simulation for the Lucas Model while the column labelled Svensson shows the simulation for the Svensson Model. Despite the simplicity of the models $\Gamma$ they perform surprisingly well. With only two parameters to calibrate $\mathrm{T}$ the preference parameter $\Gamma \beta \Gamma$ and the transaction cost parameter $\Gamma k \Gamma$ the Lucas Model presented here can approximate 9 out of the 15 moments considered for the estimations of endogenous variables computed with annual data. The Svensson Model can replicate 8 moments. The tables also show that those

\footnotetext{
${ }^{11}$ See Chang [4].
} 
moments are approximated very closely. For the Svensson model $\Gamma 7$ moments were simulated within one standard deviation of the sample value. The Lucas Model could generate 6 moments within one standard deviation of the sample value. In particular Tthe model generates a fair amount of variability in the velocity of money very close to the sample value for the Svensson Model. It also recovers the mean values for money velocity nominal interest rate. Additionally the model seems to capture some of the correlation structure found in the data. In particular it simulates very well the correlations associated with the growth rate of output and the inflation rate. The results for quarterly data are not as good as the results with annual data though. The Lucas Model can approximate only 4 moments while the Svensson Model simulates 5 correctly.

This exercise is interesting because it also shows where the model does not behave as the data. An example of this behavior is the strong positive correlation between the velocity of money and the nominal interest rate. This result of the model does not show in the data. This could be due to several reasons. First $\Gamma$ the definition of money used here could be one cause. With M2T the link between interest rate and money demand derived from the model is somewhat lost since part of this definition of money generates

interest. A second reason could be attributed to the assumed stationarity of the series. The intuition behind this prediction of the models is clear. An unexpected increase in the growth rate of money increases the expectation of inflation tomorrow. This drives the nominal interest rate up which leads to an increase in the velocity of money.

\subsection{The Welfare Costs of Inflation under Uncertainty}

In this section the Lucas Model will be used to compute the welfare cost of inflation under uncertainty. In particular $\Gamma$ this exercise tries to analyze the contribution of uncertainty in the calculations of the welfare cost of inflation. In the model $\Gamma$ this cost $\Gamma$ as a percentage of nominal output $\Gamma$ is the following function of $\theta$ :

$$
w\left(\theta_{t}\right)=\frac{K^{*}\left(\theta_{t}\right)}{P^{*}\left(\theta_{t}\right) y_{t}}=\left[N^{*}\left(\theta_{t}\right)-1\right] k=\left[\frac{(1+k) v^{*}\left(\theta_{t}\right)}{1+k v^{*}\left(\theta_{t}\right)}-1\right] k
$$

First $\Gamma$ the model is solved under certainty using annual data. The value for the growth rate of real output used is the average over the sample period which equals 1.0205 . Several values for the growth rate of money are used. 
They are shown in the first column of Tables 13 to 15 . The welfare cost of inflation for those rates of growth computed from a deterministic setting are included in the second column of Table 13 the computations under uncertainty the estimated VAR for $\gamma_{t}$ and $\mu_{t}$ is used. In this case the constant in the money growth equation is changed to make the average growth rate of money equal to the figures in the first column of Table 13. The results are included in the last column of Table 13Гlabelled 'Uncertainty'.

From Tables 13 to 15 one can see the similarity of the results when the two environments are compared. This is true even for large values of average money growth. It seems $\Gamma$ therefore $\Gamma$ that uncertainty $\Gamma$ at least in the amount observed in the data $\mathrm{Cdoes}$ not add too much to the welfare costs of inflation. In fact $\Gamma$ the model systematically predicts a lower value for these costs under uncertainty. As Table 14 shows this is because people go less to the bank on average. ${ }^{12}$ The reason for this result is as follows. Because of the logarithmic utility uncertainty in the money growth rate raises the expected marginal utility of next's period consumption. Thus Tagents will be more willing to exchange consumption today for consumption tomorrow. This drives down interest rates as Table 15 shows. As nominal interest rates go down the opportunity cost of holding money decreases and agents compensate for this change by increasing their money holdings and reducing the number of trips to the bank.

\section{Conclusions}

This paper develops a simple general equilibrium model of money demand where the velocity of money responds to endogenous changes in the interest rate as in Baumol [2] or Tobin [30]. Also Tit is shown that versions of this model nest different cash-in-advance models as particular cases for a subset of the parameter space.

A data-matching exercise reveals that despite the simplicity of the model it can perform surprisingly well especially when approximating the moments associated with the growth rate of real output and the inflation rate. The

\footnotetext{
${ }^{12}$ This does not happen at very low values for the average growth rate of money. In that case, nominal interest rates are driven to zero together with the money velocity. Since the first trip to the bank is free and $N_{t}$ is constrained to be larger than one, the model cannot capture the costs of inflation for low values of $E(\mu)$.
} 
model is then used to analyze the welfare costs of inflation under uncertainty. In particular $\Gamma$ this application addresses the issue of the size of the error generated when computing the costs of inflation with deterministic models. It turns out that the size of this error is small $\mathrm{C}$ at least for the levels of uncertainty estimated for the U.S. economy. In fact $\Gamma$ for the form of the utility function used in this paper $\Gamma$ uncertainty reduces the welfare costs of inflation.

The model can be used to look at issues in international economics. One application is the analysis of the efficiency gains derived from a monetary union and in particular Tthe model may be used to predict what gains could result from the process of monetary union in Europe. Most of the recent literature on the topic points out two main direct benefits: the elimination of transaction costs associated with exchanging currency and the suppression of exchange rate uncertainty. ${ }^{13}$ However $\Gamma$ there is currently no theoretical framework that allows all of these gains to be analyzed together.

The transaction costs of a multi-currency exchange system are measured in terms of the otherwise productive resources that households and firms need to devote to foreign exchange management. I have analyzed these costs in Rodríguez Mendizábal [24] where a liquidity cost model of money demand like the ones in Baumol [2] and Tobin [30] is generalized to include several currencies and uncertainty. When calibrated to fit European data pected savings associated with reductions of transaction costs derived from the European Monetary Union are estimated to be approximately $0.6 \%$ of Community GDP (or \$US 55 billion for 1996).

The volatility of exchange rates also generates costs within the countries belonging to the European Union. First Texchange rate variability increases uncertainty of payments and implies larger transaction costs in exchanging currencies. Second Tfirms and households spend resources in order to hedge against adverse movements of exchange rates. Finally $\mathrm{T}$ uncertainty in the exchange rate may have negative effects on trade and investment Talthough there is no consensus on this point in the literature. The partial equilibrium model in Rodríguez Mendizábal [24] cannot deal with issues regarding endogenous determination of price volatility $\Gamma$ so a general equilibrium model is needed. The model presented in this paper integrates CIA models with

\footnotetext{
${ }^{13}$ For evaluations of the main benefits and costs see, among others, Commission of the European Communities [5], De Grauwe [8], Fratiani and von Hagen [11], Gross and Thygesen [12], and Viñals [31].
} 
liquidity cost models. Thus Twhile it preserves the simple structure of CIA models Tit explicitly includes a Baumol-type transaction technology. On the other hand Tit explicitly includes a Baumol-type transaction technology which will allow me to carry over some of the conclusions derived from the partialequilibrium approach in Rodríguez Mendizábal [24] to this model. 


\section{A Proof of Propositions in the Paper}

\section{A.1 Proof of Lemma 1}

Feasible consumption sequences satisfy

$$
0 \leq c_{t} \leq y_{t}\left[1+\left(1-N_{t}\right) k\right] \leq y_{t}
$$

since $N_{t} \geq 1$ and $0<k<1$. Then

$$
\begin{aligned}
E_{0}\left[\sum_{t=0}^{\infty} \beta^{t} u\left(c_{t}\right)\right] & \leq E_{0}\left[\sum_{t=0}^{\infty} \beta^{t} u\left(y_{t}\right)\right]=E_{0}\left[\sum_{t=0}^{\infty} \beta^{t} \log \left(y_{t}\right)\right] \\
& =E_{0}\left[\log \left(y_{0}\right) \sum_{t=1}^{\infty} \beta^{t}+\sum_{t=1}^{\infty} \beta^{t}\left(\sum_{j=1}^{t} \log \left(\gamma_{j}\right)\right)\right] \\
& \leq \log \left(y_{0}\right) \frac{1}{1-\beta}+\sum_{t=1}^{\infty} \beta^{t} E_{0}\left(\sum_{j=1}^{t} \log \left(\gamma_{j}\right)\right)
\end{aligned}
$$

But

$$
E_{0}\left[\sum_{j=1}^{t} \log \left(\gamma_{j}\right)\right]=E_{0}\left[\log \left(\gamma_{1}\right)+E_{1}\left(\log \left(\gamma_{2}\right)\right)+\cdots+E_{t-1}\left(\log \left(\gamma_{t}\right)\right)\right] \leq t \bar{\alpha}
$$

where

$$
\bar{\alpha}=\sup \left[\beta \int_{\Theta} \log \left(\gamma^{\prime}\right) Q\left(\theta, d \theta^{\prime}\right)\right] .
$$

By Assumption $3 \bar{\alpha}<\infty$. Then

$$
E_{0}\left[\sum_{t=0}^{\infty} \beta^{t} u\left(c_{t}\right)\right] \leq \bar{u}<\infty
$$

with

$$
\bar{u}=\frac{\log \left(y_{0}\right)}{1-\beta}+\bar{\alpha} \sum_{t=1}^{\infty} t \beta^{t}
$$

being the finite upper bound. Q.E.D. 


\section{A.2 Proof of Proposition 1}

For a given value of $N_{t}^{h}$ The agent will choose intervals between trips and sizes of withdrawals so as to minimize the opportunity cost of holding currency $\Gamma$ that is $\Gamma$

$$
O C_{t}^{h}=\left(1+i_{t}\right)\left[W_{t}^{h}-\sum_{s=1}^{N_{t}^{h}}\left(\Delta t_{s} \sum_{r=1}^{s} M_{t}^{h}(r)\right)\right] .
$$

Given the constant flow of expenditures within each period $\Gamma \Delta t_{s}$ will satisfy

$$
\Delta t_{s}=\frac{M_{t}^{h}(s)}{\widehat{M}_{t}^{h}} \quad \text { so that } \quad \sum_{s=1}^{N_{t}^{h}} \Delta t_{s}=1 \text {, }
$$

so $O C_{t}^{h}$ may be written as

$$
O C_{t}^{h}=\left(1+i_{t}\right)\left[W_{t}^{h}-\widehat{M}_{t}^{h} \sum_{s=1}^{N_{t}^{h}}\left(\Delta t_{s} \sum_{r=1}^{s} \Delta t_{r}\right)\right]
$$

The first order condition for a minimum with respect to an arbitrary interval $\Delta t_{s}$ takes the form

$$
\Delta t_{s}+\sum_{n=1}^{N_{t}^{h}-1} \Delta t_{n}-1=0
$$

or $\Gamma$

$$
\Delta t_{s}=1-\sum_{n=1}^{N_{t}^{h}-1} \Delta t_{n}
$$

Since the right side of this expression does not depend on $s$ it turns out that $\Delta t_{s}=\Delta t_{r}$ all $s \Gamma r$ or $\Gamma$

$$
\Delta t_{s}=\frac{1}{N_{t}^{h}}
$$

so that

$$
\widehat{M}_{t}^{h}=N_{t}^{h} M_{t}^{h} .
$$

Q.E.D. 


\section{A.3 Proof of Proposition 2}

First $\Gamma$ it is possible to prove that $T: \mathcal{V}(\mathcal{S}) \rightarrow \mathcal{V}(\mathcal{S})$. From $(24)$ Tthe constraint set is compact. By Assumption $2 \Gamma u$ is continuous in $c$. Also $\Gamma$ since $v \in \mathcal{V}(\mathcal{S}) \Gamma$ $E\left[v\left(s^{\prime}\right) \mid \theta\right]$ is continuous by Assumption 1. Then $T v$ involves maximizing a continuous function over a compact set so that a maximum exists and $\Gamma$ by the Theorem of the Maximum it is continuous. Since $u(c)$ is bounded in the constraint set and $v \in \mathcal{V}(\mathcal{S}) \Gamma T v$ is also bounded. Thus $\Gamma T$ maps $\mathcal{V}(\mathcal{S})$ into itself.

Next Tit is straightforward to show that $T$ satisfies Blackwell's sufficient conditions for a contraction. Given any two functions $f, g \in \mathcal{V}(\mathcal{S})$ एsuch that $f \geq g$ it is easy to see that $T f \geq T g \Gamma$ so that $T$ is monotone. To verify discounting $\Gamma$ for any constant $a>0 \Gamma$

$$
\begin{aligned}
T(v+a)(s) & =\max \left\{u(c)+\beta \int_{\Theta}\left[v\left(s^{\prime}\right)+a\right] Q\left(\theta, d \theta^{\prime}\right)\right\} \\
& =\max \left\{u(c)+\beta \int_{\Theta}\left[v\left(s^{\prime}\right)\right] Q\left(\theta, d \theta^{\prime}\right)\right\}+\beta a \\
& =T v(s)+\beta a .
\end{aligned}
$$

Hence $\Gamma T$ satisfies Blackwell's conditions for a contraction and since $\mathcal{V}(\mathcal{S})$ is a completeГnormed $\Gamma$ linear space $\Gamma$ by the Contraction Mapping Theorem $T$ has a unique fixed point. Q.E.D.

\section{A.4 Proof of Proposition 3}

To show that $v$ is an increasing and concave function of $w \Gamma$ let $\mathcal{C}(\mathcal{S})$ be the space of continuous Cbounded Tincreasing Tand concave functions $f: \mathcal{S} \rightarrow R_{+}$ with the sup norm. Notice that $\mathcal{C}(\mathcal{S})$ is a closed subset of $\mathcal{V}(\mathcal{S})$. Then for any increasing function of $w \Gamma f \Gamma T f$ is also an increasing function of $w$.

To show that $T$ preserves concavity $\Gamma$ let $w_{\lambda}=\lambda w_{1}+(1-\lambda) w_{2} \Gamma \lambda \in[0,1]$. Let $\left(m_{j}^{d}, c_{j}, b_{j}\right)$ attain $(T v)\left(w_{j}, \theta\right) \Gamma(j=1,2)$. Also define correspondingly $m_{\lambda}^{d} \Gamma c_{\lambda} \Gamma$ and $b_{\lambda}$. It is clear that $\left(m_{\lambda}^{d}, c_{\lambda}, b_{\lambda}\right)$ satisfies

$$
\begin{gathered}
b_{\lambda}+m_{\lambda}^{d} \leq w_{\lambda} \\
\frac{p c_{\lambda}}{m_{\lambda}^{d}} \geq 1
\end{gathered}
$$

and

$$
m_{\lambda}^{d} \in \mathcal{M} \quad b_{\lambda} \in \mathcal{B} \quad 0 \leq c_{\lambda} \leq y
$$


so this allocation is feasible at $\left(y, w_{\lambda}, \theta\right)$ Talthough it may not be optimal. Let $\left(m_{*}^{d}, c_{*}, b_{*}\right)$ attain $(T v)\left(w_{\lambda}, \theta\right)$ and define

$$
\begin{aligned}
w_{j}^{\prime}= & w^{\prime}\left(m_{j}^{d}, c_{j}, b_{j}\right)=1+\frac{1}{\mu^{\prime}}\left[(1+i) b_{j}+\left(1+\frac{i}{2}\right) m_{j}^{d}-\left(1+\frac{i}{2}\right) p c_{j}\right. \\
& +i \bar{b}^{a}+p y-\left(\frac{p c_{j}}{m_{j}^{d}}-1\right) k p y
\end{aligned}
$$

for $j=1,2, \lambda, *$. Then for any concave function $v \Gamma$

$$
\begin{aligned}
(T v)\left(y, w_{\lambda}, \theta\right)= & u\left(c_{*}\right)+\beta E\left[v\left(y^{\prime}, w_{*}^{\prime}, \theta^{\prime}\right) \mid \theta\right] \geq u\left(c_{\lambda}\right)+\beta E\left[v\left(y^{\prime}, w_{\lambda}^{\prime}, \theta^{\prime}\right) \mid \theta\right] \\
\geq & u\left(c_{\lambda}\right)+\beta E\left[v\left(y^{\prime}, \lambda w_{1}^{\prime}+(1-\lambda) w_{2}^{\prime}, \theta^{\prime}\right) \mid \theta\right] \\
\geq & \lambda u\left(c_{1}\right)+(1-\lambda) u\left(c_{2}\right)+\lambda \beta E\left[v\left(y^{\prime}, w_{1}^{\prime}, \theta^{\prime}\right) \mid \theta\right] \\
& +(1-\lambda) \beta E\left[v\left(y^{\prime}, w_{2}^{\prime}, \theta^{\prime}\right) \mid \theta\right] \\
\geq & \lambda(T v)\left(y, w_{1}, \theta\right)+(1-\lambda)(T v)\left(y, w_{2}, \theta\right) .
\end{aligned}
$$

The second inequality appears both from the fact that $w^{\prime}$ is a concave function of $\left(m_{\lambda}^{d}, c_{\lambda}, b_{\lambda}\right)$ and $v$ is an increasing function of $w$. Since $\mathcal{C}(\mathcal{S})$ is a closed subset of $\mathcal{V}(\mathcal{S}) \Gamma$ and $T$ is a contraction $\Gamma$ then $v^{*} \in \mathcal{C}(\mathcal{S})$ so it is increasing and concave. ${ }^{14}$

Finally this problem satisfies the assumptions of the Theorem of Benveniste and Scheinkman [3] so $^{*}$ is continuously differentiable with respect to $w$. Q.E.D.

\section{A.5 Proof of Proposition 4}

Proposition 4 is a particular case of Proposition 17.5 in Stokey and Lucas [28] which is stated next.

Proposition 8. Let $\Theta$ be a bounded set; let $\mathcal{V}(\Theta)$ be the space of bounded continuous functions on $\Theta$ Twith the sup norm; and let $F \subset \mathcal{V}(\Theta)$ be closed and bounded. Assume that the operator $T: F \rightarrow F$ is continuous and monotone and that $T(F)$ is an equicontinuous family. If for $f_{0}(\theta)=\delta_{k}$ and $g_{0}(\theta)=1$ all $\theta \in \Theta$ Tit turns out that

$$
\lim _{n \rightarrow \infty} T^{n} f_{0}=f=g=\lim n \rightarrow \infty T^{n} g_{0}
$$

then this function is the unique fixed point of $T$.

\footnotetext{
${ }^{14}$ See Stokey and Lucas [28], Corollary 1 pg. 52.
} 
Define the operator $T$ as

$$
(T f)(\theta)=\int_{\Theta} G\left[\theta, \theta^{\prime}, f\left(\theta^{\prime}\right)\right] Q\left(\theta, d \theta^{\prime}\right),
$$

with

$$
G\left[\theta, \theta^{\prime}, f\left(\theta^{\prime}\right)\right]=\beta \Phi[v(f(\theta) ; \theta)] \frac{f\left(\theta^{\prime}\right)}{\mu^{\prime}}-2 \lambda(f(\theta) ; \theta) .
$$

where $v(f(\theta) ; \theta)$ and $\lambda(f(\theta) ; \theta)$ were defined in (41) and (42) Гrespectively.

In order to apply Proposition 17.5 in Stokey and Lucas [28] a space of functions $F \in \mathcal{V}(\Theta)$ has to be chosen. Let $F$ be the space of continuous functions

$$
f: \Theta \rightarrow\left[\delta_{k}, 1\right]
$$

Clearly $\Gamma$ is nonempty $\Gamma$ closed $\Gamma$ bounded $\Gamma$ and convex.

NextTI need to show that the operator $T$ maps $F$ into itself. Pick any continuous function $f \in F$. Then for $\theta \in \widehat{\Theta}^{c} \Gamma$ so that $v[f(\theta) ; \theta]=1 \Gamma$

$$
(T f)(\theta)=\beta[1+2 k] \int_{\Theta}\left(\frac{f\left(\theta^{\prime}\right)}{\mu^{\prime}}\right) Q\left(\theta, d \theta^{\prime}\right)-2 \lambda[f(\theta) ; \theta]=1 .
$$

On the other hand $\Gamma$ for $\theta \in \widehat{\Theta} \Gamma$ so that $v[f(\theta) ; \theta]>1$ Tand $\lambda[f(\theta) ; \theta]=0 \Gamma$

$$
\begin{aligned}
(T f)(\theta) & =\beta \Phi[v(f(\theta) ; \theta)] \int_{\Theta}\left(\frac{f\left(\theta^{\prime}\right)}{\mu^{\prime}}\right) Q\left(\theta, d \theta^{\prime}\right) \\
& \geq \beta \Omega[v(f(\theta) ; \theta)] \int_{\Theta}\left(\frac{f\left(\theta^{\prime}\right)}{\mu^{\prime}}\right) Q\left(\theta, d \theta^{\prime}\right) \geq \Psi[v(f(\theta) ; \theta)] \\
& \geq \frac{k}{1+k}=\delta_{k}
\end{aligned}
$$

and

$$
\begin{aligned}
(T f)(\theta) & =\beta \Phi[v(f(\theta) ; \theta)] \int_{\Theta}\left(\frac{f\left(\theta^{\prime}\right)}{\mu^{\prime}}\right) Q\left(\theta, d \theta^{\prime}\right) \\
& =\Phi[v(f(\theta) ; \theta)] \Psi[v(f(\theta) ; \theta)] \Omega[v(f(\theta) ; \theta)]^{-1}<1 .
\end{aligned}
$$

Also $\Gamma$ since $Q$ has the Feller property and $f$ is continuous $\Gamma v[f(\theta) ; \theta]$ is continuous and so is $T f$. Then $T: F \rightarrow F$.

Next $\Gamma$ need to prove that the operator $T$ is continuous and monotone and that $T(F)$ is an equicontinuous family. The operator $T$ forms an equicontinuous family since $\mathcal{D}$ is nonempty $\Gamma$ closed $\Gamma$ bounded and convex $\Gamma G$ is continuous 
and uniformly continuous in its first argument. $T$ is also continuous as an operator since $G$ is uniformly continuous in its third argument. Finally $T T$ is monotone since it is linear in $f$.

The last step in the proof is to show

$$
\lim _{n \rightarrow \infty} T^{n} f_{0}=f=g=\lim _{n \rightarrow \infty} T^{n} g_{0}
$$

For $f_{0}(\theta)=\delta_{k} \Gamma$

$$
\left(T f_{0}\right)(\theta)=\beta \Phi[v(f(\theta) ; \theta)] \int_{\Theta}\left(\frac{f\left(\theta^{\prime}\right)}{\mu^{\prime}}\right) Q\left(\theta, d \theta^{\prime}\right) \delta_{k}-2 \lambda[f(\theta) ; \theta]
$$

with $v(f(\theta) ; \theta)$ satisfying

$$
\Psi[v(f(\theta) ; \theta)]=\beta \Phi[v(f(\theta) ; \theta)] \int_{\Theta}\left(\frac{f\left(\theta^{\prime}\right)}{\mu^{\prime}}\right) Q\left(\theta, d \theta^{\prime}\right) \delta_{k}-2 \lambda[f(\theta) ; \theta]
$$

On the other hand $\Gamma$ for $g_{0}(\theta)=1 \Gamma$

$$
\left(T g_{0}\right)(\theta)=\beta \Phi[v(f(\theta) ; \theta)] \int_{\Theta}\left(\frac{1}{\mu^{\prime}}\right) Q\left(\theta, d \theta^{\prime}\right)-2 \lambda[f(\theta) ; \theta]
$$

with $v(f(\theta) ; \theta)$ satisfying

$$
\Psi[v(f(\theta) ; \theta)]=\beta \Phi[v(f(\theta) ; \theta)] \int_{\Theta}\left(\frac{1}{\mu^{\prime}}\right) Q\left(\theta, d \theta^{\prime}\right)-2 \lambda[f(\theta) ; \theta] .
$$

It is easy to see that $\left(T f_{0}\right)(\theta)=\left(T g_{0}\right)(\theta)$ for all $\theta \in \Theta$. Then $\Gamma$ by induction

$$
\lim _{n \rightarrow \infty} T^{n} f_{0}=f=g=\lim _{n \rightarrow \infty} T^{n} g_{0},
$$

so that there exists a unique fixed point of $T$.

Call $\delta^{*}(\theta)$ the fixed point associated with $T$. Define

$$
v^{*}(\theta) \equiv v\left[\delta^{*}(\theta) ; \theta\right] \quad \text { and } \quad \lambda^{*}(\theta) \equiv \lambda\left[\delta^{*}(\theta) ; \theta\right] .
$$

From (84) define the function $i^{*}(\theta)$ as

$$
i^{*}(\theta)=2\left[k \frac{(1+k) v^{*}(\theta)^{2}}{1+k v^{*}(s)}-\frac{\lambda^{*}(\theta)}{\beta L\left(\delta^{*}(\theta) ; \theta\right)}\right] .
$$


Assumption 4 ensures that $i(\theta)>0 \Gamma$ for all $\theta \in \Theta$. For $\theta \in \widehat{\Theta}^{c} \Gamma$ $i^{*}(\theta)=2\left[k-\frac{\beta(1+2 k) L\left(\delta^{*}(\theta) ; \theta\right)-1}{2 \beta L\left(\delta^{*}(\theta) ; \theta\right)}\right]=\frac{1}{\beta L\left(\delta^{*}(\theta) ; \theta\right)}\left[1-\beta L\left(\delta^{*}(\theta) ; \theta\right)\right]$.

Since $\delta^{*}(\theta) \in[0,1] \Gamma$

$$
1>\beta \int_{\Theta}\left(\frac{1}{\mu^{\prime}}\right) Q\left(\theta, d \theta^{\prime}\right)
$$

is a sufficient condition for $i^{*}(\theta)>0$. For $\theta \in \widehat{\Theta} \Gamma$

$$
i^{*}(\theta)=2 k \frac{(1+k) v^{*}(\theta)^{2}}{1+k v^{*}(\theta)}>0 .
$$

\section{Q.E.D.}

\section{A.6 Proof of Proposition 5}

The value $\bar{k}$ is equal to

$$
\bar{k}=\frac{1}{2}\left[\frac{1}{\beta \underline{L}}-1\right]
$$

where

$$
\underline{L}=\min \left\{\int_{\Theta}\left(\frac{\delta^{*}\left(\theta^{\prime}\right)}{\mu^{\prime}}\right) Q\left(\theta, d \theta^{\prime}\right)\right\} .
$$

To prove this proposition it is sufficient to show that the functions $v^{*}(\theta)=$ $1 \Gamma \delta^{*}(\theta)=1$ Tand

$$
\lambda^{*}(\theta)=\frac{1}{2}\left[\beta(1+2 k) \int_{\Theta} \frac{1}{\mu^{\prime}} Q\left(\theta, d \theta^{\prime}\right)-1\right]
$$

form a solution to the system of equations (35)-(37). Given the function $\delta^{*}(\theta)=1 \Gamma$ for any $k \geq \bar{k}$ expression (40) implies that $\widehat{\Theta}=\varnothing$ and $\hat{\Theta}^{c}=\Theta$. Then for all $\theta \in \Theta \Gamma v^{*}(\theta)=1$ so that the constraint $N \geq 1$ is binding. This corroborates the initial assumption $\delta^{*}(\theta)=1$ all $\theta \in \Theta$. The value for $\lambda^{*}(\theta)$ is determined by (36).

$$
\text { Q.E.D. }
$$




\section{A.7 Proof of Proposition 6}

Define the operator $T$ as

$$
(T f)(\theta)=\int_{\Theta} G\left[\theta, \theta^{\prime}, f\left(\theta^{\prime}\right)\right] Q\left(\theta, d \theta^{\prime}\right),
$$

where

$$
\begin{aligned}
G\left[\theta, \theta^{\prime}, f\left(\theta^{\prime}\right)\right]= & \frac{\beta}{\mu} f\left(\theta^{\prime}\right)\left[1+2 k v\left(f\left(\theta^{\prime}\right) ; \theta^{\prime}\right) N\left(f\left(\theta^{\prime}\right) ; \theta^{\prime}\right)\right]-2 \frac{\beta}{\mu} \lambda\left(f\left(\theta^{\prime}\right) ; \theta^{\prime}\right) \\
= & \frac{\beta}{\mu} f\left(\theta^{\prime}\right)\left[1+\frac{i(f(\theta) ; \theta)}{2}+k v\left(f\left(\theta^{\prime}\right) ; \theta^{\prime}\right) N\left(f\left(\theta^{\prime}\right) ; \theta^{\prime}\right)\right] \\
& -2 \frac{\beta}{\mu} \lambda\left(f\left(\theta^{\prime}\right) ; \theta^{\prime}\right)
\end{aligned}
$$

where $v(f(\theta) ; \theta) \Gamma N(f(\theta) ; \theta) \Gamma i(f(\theta) ; \theta) \Gamma$ and $\lambda(f(\theta) ; \theta)$ are defined implicitly by the system (74)-(78). It is easy to show that for $\theta^{\prime} \in \Theta_{1} \Gamma$

$$
G\left[\theta, \theta^{\prime}, f\left(\theta^{\prime}\right)\right]=\frac{\beta}{\mu} f\left(\theta^{\prime}\right) \text {. }
$$

For $\theta^{\prime} \in \Theta_{2} \Gamma$

$$
G\left[\theta, \theta^{\prime}, f\left(\theta^{\prime}\right)\right]=\frac{\beta}{\mu} .
$$

Furthermore $\Gamma$ for $\theta^{\prime} \in \Theta_{3} \Gamma$

$$
G\left[\theta, \theta^{\prime}, f\left(\theta^{\prime}\right)\right]=\frac{\beta}{\mu} f\left(\theta^{\prime}\right)\left[1+2 k \frac{(1+k) v\left(f\left(\theta^{\prime}\right) ; \theta^{\prime}\right)^{2}}{1+k v\left(f\left(\theta^{\prime}\right) ; \theta^{\prime}\right)}\right] .
$$

The same steps used to prove Proposition 5 can be used here. The only difference appears from the new subset $\Theta_{1}$. As in Svensson [29] $\Gamma$ a problem may arise when $\mu$ is small enough. In order to ensure that an equilibrium exists it is necessary to assume a strictly positive lower bound $\varepsilon$ to the growth rate of money. Q.E.D.

\section{A.8 Proof of Proposition 7}

This proof shows that there exists such a $\bar{k}$. For every pair $\left(\theta^{0}, \theta\right)$ T there is always a $k\left(\theta^{0}, \theta\right)$ such that

$$
1<\delta(\theta)\left[1+k\left(\theta^{0}, \theta\right)+\frac{i\left(\theta^{\circ}\right)}{2}\right] .
$$

Choose then $\bar{k}=\max \left\{k\left(\theta^{0}, \theta\right)\right\}$ Q.E.D. 


\section{B Computation of Expression (44)}

In this Appendix it is shown that $\mathcal{D}=\left[\delta_{k}, 1\right]$ with

$$
\delta_{k}=\frac{k}{1+k} .
$$

For $\theta \in \widehat{\Theta}^{c} \Gamma \delta=1$. For $\theta \in \widehat{\Theta}$ we have the two equations

$$
\Psi(v)=\beta \Omega(v) \int_{\Theta} \frac{\delta\left(\theta^{\prime}\right)}{\mu^{\prime}} Q\left(\theta, d \theta^{\prime}\right)
$$

and

$$
\delta=\beta \Phi(v) \int_{\Theta} \frac{\delta\left(\theta^{\prime}\right)}{\mu^{\prime}} Q\left(\theta, d \theta^{\prime}\right)
$$

or $\Gamma$

$$
\Psi(v)=\Omega(v) \frac{\delta}{\Phi(v)} .
$$

From this expression it is possible to write $\delta$ as a function of $v$

$$
\delta=h(v)=\frac{\Psi(v) \Phi(v)}{\Omega(v)} .
$$

After some algebra it is easy to prove that

$$
\frac{d h(v)}{d v}<0
$$

Then Tthe lower bound for $\delta$ appears from

$$
\lim _{v \rightarrow \infty} h(v)=\frac{2 k}{1+2 k}>\frac{k}{1+k}=\delta_{k} .
$$

\section{Q.E.D.}

\section{Description of the series}

The data source is the Citibase database. The data for each year is the last observation of that year. The series cover from 1959 to 1996. The variables are (Citibase acronyms in parenthesis) 
- Real income: Gross Domestic Product in 1987 dollars (GDPQ)

- Nominal income: Gross Domestic Product in current dollars (GDP)

- Prices: Gross Domestic ProductTimplicit price deflator (GDPD)

- Money: either M1 money stock (FM1) or M2 money stock (FM2)

- Nominal interest rates: US Treasury Bills $\Gamma 1$ year (FYGMYR)

Velocity of money is computed as nominal income divided by a definition of money stock. 


\section{References}

[1] AlvarezГF. and A. Atkenson (1996): "Liquidity InflationCInterest Rates and Exchange Rates" mimeorUniversity of Pennsylvania.

[2] BaumolГ W. J. (1952): "The Transaction Demand for Cash: An Inventory-Theoretic Approach" Quarterly Journal of Economics 66 (4): 545-556.

[3] BenvenisteГL. M.Гand J. A. Scheinkman (1979): "On the Differentiability of the Value Function in Dynamic Models of Economics" Econometrica $47: 727-732$.

[4] Chang FF. R. (1992): "Homogeneity and the Transactions Demand for Money" Unpublished paper Indiana University.

[5] Commission of the European Communities (1990): "One Market One Money: An Evaluation of the Potential Benefits and Costs of Forming and Economic and Monetary Union" European Economy 44TOctober.

[6] Den HaanTW. J. (1990): "The Optimal Inflation Path in a SidrauskiType Model with Uncertainty" Journal of Monetary Economics 25: 389409.

[7] Den Haan Г W. J. and A. Marcet (1994): "Accuracy in Simulations" Review of Economic Studies 61: 3-17.

[8] De GrauweГP. (1994): The Economics of Monetary Integration OOxford University Press.

[9] DotseyГ M. and P. Ireland (1996): "The Welfare Cost of Inflation in General Equilibrium" Journal of Monetary Economics 37: 29-47.

[10] FeenstraГ R. C. (1986): "Functional Equivalence Between Liquidity Costs and the Utility of Money" Journal of Monetary Economics 17: 271-291.

[11] FratianiГM. and J. von Hagen (1992): The European Monetary System and European Monetary UnionTBoulderTColo.: Westview Press. 
[12] Gross $\Gamma$ D. and N. Thygesen (1992): European Monetary Integration $\Gamma$ London: Longman.

[13] GrossmanTS. and L. Weiss (1983): "A Transactions-Based Model of the Monetary Transmission Mechanism" American Economic Review $\Gamma 73(5)$ : 871-880.

[14] GuidottiГP. E. (1989): "Exchange Rate Determination Interest Rates $\Gamma$ and an Integrative Approach to the Demand for Money" Journal of International Money and Finance 8: 29-45.

[15] GuidottiГP. E. and C. A. Végh (1993): "The Optimal Inflation Tax when Money Reduces Transactions Costs" Journal of Monetary Economics 31: 189-205.

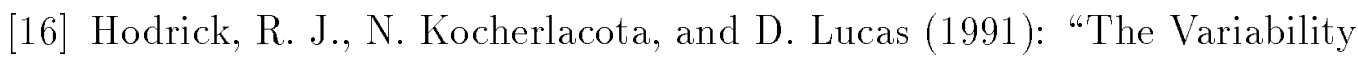
of Velocity in Cash-in-Advance Models" Journal of Political Economy 99: $358-384$.

[17] JovanovicГB. (1982): "Inflation and Welfare in the Steady State" Journal of Political Economy 90(3): 561-577.

[18] LucasTR. E. Jr. (1980): "Equilibrium in a Pure Currency Economy" in Models of Monetary Economics Tedited by J. H. Kareken and N. WallaceГ Federal Reserve Bank of Minneapolis.

[19] Lucas[R. E. Jr. (1984): "Money in the Theory of Finance" CarnegieRochester Conference Series in Public Policy 29: 137-167.

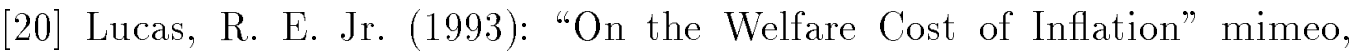
University of Chicago.

[21] LucasTR. E. Jr. and Nancy L. Stokey (1987): "Money and Interest in a Cash-in-Advance Economy" Econometrica 55: 491-513.

[22] MarcetГA. (1988): "Solving Non-Linear Models by Parameterized Expectations" Tmimeo CCarnegie Mellon University.

[23] MarshallГ D. A. (1992): "Inflation and Asset Returns in a Monetary Economy" Journal of Finance 48(4): 1315-1342. 
[24] Rodríguez MendizábalГH. (1998): "Monetary Unions and the Transaction Costs Savings of a Single Currency" Universitat Pompeu Fabra Working Paper No. 291.

[25] RotembergГJ. J. (1984): "A Monetary Equilibrium Model with Transactions Costs" Journal of Political Economy 92(1): 40-58.

[26] Schreft Г S. L. (1992): "Transaction Costs and the Use of Cash and Credit" Economic Theory 2: 283-296.

[27] StockГJ. and M. Watson (1989): "Interpreting the Evidence on MoneyIncome Causality" Journal of Econometrics 40: 161-181.

[28] Stokey TN. L. and R. E. LucasTwith E. Prescott (1989): Recursive Methods in Economic Dynamics CambridgeГMA. Harvard University Press.

[29] SvenssonT L. E. O. (1985): "Money and Asset Prices in a Cash-inAdvance Model" Journal of Political Economy 93: 919-944.

[30] TobinГJ. (1956): "The Interest Elasticity of the Transactions Demand for Cash" Review of Economic and Statistics 38 (3): 241-247.

[31] ViñalsГJ. (1994): "Building a Monetary Union in Europe: Is it Worthwhile Where Do We StandTand Where Are We Going?" CEPR Occasional Paper 15. 
Table 1

Augmented Dickey-Fuller ( $A D F$ ) Tests: Annual DataГ1959-96

\begin{tabular}{|c|ccc|cc|}
\hline $\begin{array}{c}\text { Dependent } \\
\text { variable }\end{array}$ & $\alpha_{0}$ & $\alpha_{1}$ & $\alpha_{2}$ & ADF ${ }^{a}$ & ${\text { Wald }-F^{b}}^{b}$ \\
\hline$\gamma_{t}$ & 0.93249 & -0.00068 & 0.09953 & -5.50 & 15.30 \\
& $(0.16877)$ & $(0.00039)$ & $(0.16359)$ & & \\
\hline$\mu_{t}$ & 0.53174 & -0.00086 & 0.51369 & -3.42 & 6.16 \\
& $(0.15408)$ & $(0.00044)$ & $(0.14221)$ & & \\
\hline$v_{t}$ & 0.27837 & 0.00242 & 0.81776 & -1.63 & 2.48 \\
& $(0.17824)$ & $(0.00109)$ & $(0.11181)$ & & \\
\hline$\pi_{t}$ & 0.01026 & -0.00025 & 0.86926 & -1.44 & 1.92 \\
& $(0.00579)$ & $(0.00021)$ & $(0.09086)$ & & \\
\hline$i_{t}$ & 0.01511 & -0.00004 & 0.78526 & -2.02 & 2.42 \\
& $(0.00723)$ & $(0.00025)$ & $(0.10616)$ & & \\
\hline
\end{tabular}

Table 2

Augmented Dickey-Fuller ( $A D F$ ) Tests: Quarterly DataГ1959-96

\begin{tabular}{|c|ccc|cc|}
\hline $\begin{array}{c}\text { Dependent } \\
\text { variable }\end{array}$ & $\alpha_{0}$ & $\alpha_{1}$ & $\alpha_{2}$ & ADF ${ }^{a}$ & ${\text { Wald }-F^{b}}^{b}$ \\
\hline$\gamma_{t}$ & 0.74897 & -0.00002 & 0.25661 & -9.12 & 41.58 \\
& $(0.08113)$ & $(0.00002)$ & $(0.08053)$ & & \\
\hline$\mu_{t}$ & 0.31551 & -0.00002 & 0.69086 & -5.30 & 14.18 \\
& $(0.15408)$ & $(0.00044)$ & $(0.14221)$ & & \\
\hline$v_{t}$ & 0.07801 & 0.00015 & 0.94936 & -2.28 & 4.46 \\
& $(0.03500)$ & $(0.00005)$ & $(0.02220)$ & & \\
\hline$\pi_{t}$ & 0.00129 & -0.00001 & 0.91561 & -1.87 & 2.22 \\
& $(0.00070)$ & $(0.00001)$ & $(0.04509)$ & & \\
\hline$i_{t}$ & 0.00110 & 0.00001 & 0.92299 & -2.91 & 4.52 \\
& $(0.00042)$ & $(0.00001)$ & $(0.02646)$ & & \\
\hline
\end{tabular}

Notes to tables: Standard errors in parenthesis.

a The critical values for the $A D F$ test are $-3.56(5 \%)$ and $-3.22(10 \%)$.

${ }^{c}$ The critical values for the $\mathrm{F}$ test are $7.04(5 \%)$ and $5.79(10 \%)$. 
Table 3

Estimated VAR(1) for $\left(\mu_{t}, \gamma_{t}\right)$ : Annual Data 1959-96

\begin{tabular}{|c|ccc|c|cc|}
\hline $\begin{array}{c}\text { Dependent } \\
\text { Variable }\end{array}$ & Constant & $\mu_{t-1}$ & $\gamma_{t-1}$ & $R^{2}$ & $\sigma$ & $\rho_{\mu \gamma}$ \\
\hline$\mu_{t}$ & 0.792 & 0.739 & -0.504 & 0.491 & 0.023 & 0.153 \\
& $(0.181)$ & $(0.128)$ & $(0.169)$ & & & \\
\hline$\gamma_{t}$ & 0.689 & 0.267 & 0.048 & 0.146 & 0.022 & \\
& $(0.172)$ & $(0.120)$ & $(0.163)$ & & & \\
\hline
\end{tabular}

Table 4

Estimated VAR(1) for $\left(\mu_{t}, \gamma_{t}\right)$ : Quarterly Data 1959-96

\begin{tabular}{|c|ccc|c|cc|}
\hline $\begin{array}{c}\text { Dependent } \\
\text { Variable }\end{array}$ & Constant & $\mu_{t-1}$ & $\gamma_{t-1}$ & $R^{2}$ & $\sigma$ & $\rho_{\mu \gamma}$ \\
\hline$\mu_{t}$ & 0.358 & 0.744 & -0.097 & 0.541 & 0.006 & 0.024 \\
& $(0.070)$ & $(0.057)$ & $(0.053)$ & & & \\
\hline$\gamma_{t}$ & 0.529 & 0.249 & 0.223 & 0.125 & 0.009 & \\
& $(0.105)$ & $(0.085)$ & $(0.079)$ & & & \\
\hline
\end{tabular}

Notes to tables: Standard errors in parenthesis. 
Table 5

Estimated Coefficients in PEA: Annual dataГ1959-96 ${ }^{a}$

\begin{tabular}{|c|c|c|c|c|c|}
\hline & Value & & Value & & Value \\
\hline$a_{1}$ & 0.5895 & $b_{1}^{1}$ & 0.5809 & $b_{1}^{2}$ & 1.5583 \\
$a_{2}$ & -1.2917 & $b_{2}^{1}$ & -1.2917 & $b_{2}^{2}$ & 1.1256 \\
$a_{3}$ & 1.0613 & $b_{3}^{1}$ & 1.0613 & $b_{3}^{2}$ & -0.9289 \\
$a_{4}$ & -0.8398 & $b_{4}^{1}$ & -0.8378 & $b_{4}^{2}$ & 0.5398 \\
$a_{5}$ & -0.0764 & $b_{5}^{1}$ & 0.0758 & $b_{5}^{2}$ & -0.1334 \\
$a_{6}$ & 1.4630 & $b_{6}^{1}$ & 1.4602 & $b_{6}^{2}$ & -0.8514 \\
\hline
\end{tabular}

Table 6

Estimated Coefficients in PEA: Quarterly dataГ1959-96 ${ }^{a}$

\begin{tabular}{|c|c|c|c|c|c|}
\hline & Value & & Value & & Value \\
\hline$a_{1}$ & 0.5886 & $b_{1}^{1}$ & 0.5850 & $b_{1}^{2}$ & 1.6671 \\
$a_{2}$ & -2.3441 & $b_{2}^{1}$ & -2.3432 & $b_{2}^{2}$ & 2.2545 \\
$a_{3}$ & 0.3737 & $b_{3}^{1}$ & 0.3736 & $b_{3}^{2}$ & -0.3612 \\
$a_{4}$ & 2.0137 & $b_{4}^{1}$ & 2.0159 & $b_{4}^{2}$ & -1.9648 \\
$a_{5}$ & 2.3303 & $b_{5}^{1}$ & 2.3292 & $b_{5}^{2}$ & -2.2477 \\
$a_{6}$ & -2.0562 & $b_{6}^{1}$ & -2.0557 & $b_{6}^{2}$ & 2.0223 \\
\hline
\end{tabular}

Table 7

Accuracy tests: Annual data $1959-96^{b}$

\begin{tabular}{|l|cc|}
\hline & Lower 5\% & Upper 5\% \\
\hline Lucas Model & $3.5 \%$ & $6.5 \%$ \\
\hline Svensson Model & $2.0 \%$ & $8.0 \%$ \\
\hline
\end{tabular}

Table 8

Accuracy tests: Quarterly data $1959-96^{b}$

\begin{tabular}{|l|cc|}
\hline & Lower 5\% & Upper 5\% \\
\hline Lucas Model & $4.5 \%$ & $3.0 \%$ \\
\hline Svensson Model & $5.5 \%$ & $4.5 \%$ \\
\hline
\end{tabular}

Notes to tables: Standard errors in parenthesis.

a Sample size: 5000 observations

${ }^{c}$ Tests computed using 200 samples of 1000 observations 
Table 9

Models Results vs. Sample Values: Annual DataГ1959-96

Means and Standard Deviations

\begin{tabular}{|l|c|c|c|}
\hline Moment & U.S. data & Lucas & Svensson \\
\hline$E\left[\gamma_{t}\right]$ & $1.020(0.004)$ & $1.021^{* *}$ & $1.021^{* *}$ \\
$\sigma\left[\gamma_{t}\right]$ & $0.024(0.002)$ & $0.024^{* *}$ & $0.024^{* *}$ \\
$E\left[\mu_{t}\right]$ & $1.060(0.008)$ & $1.060^{* *}$ & $1.060^{* *}$ \\
$\sigma\left[\mu_{t}\right]$ & $0.033(0.004)$ & $0.034^{* *}$ & $0.034^{* *}$ \\
\hline$E\left[v_{t}\right]$ & $1.730(0.029)$ & $1.733^{* *}$ & $1.746^{* *}$ \\
$\sigma\left[v_{t}\right]$ & $0.111(0.024)$ & $0.070^{*}$ & $0.113^{* *}$ \\
$E\left[\pi_{t}\right]$ & $0.043(0.006)$ & $0.041^{* *}$ & $0.042^{* *}$ \\
$\sigma\left[\pi_{t}\right]$ & $0.026(0.004)$ & 0.065 & 0.084 \\
$E\left[i_{t}\right]$ & $0.063(0.006)$ & $0.069^{* *}$ & $0.069^{* *}$ \\
$\sigma\left[i_{t}\right]$ & $0.024(0.004)$ & 0.006 & 0.006 \\
\hline
\end{tabular}

Table 10

Models Results vs. Sample Values: Annual DataГ1959-96

Correlations

\begin{tabular}{|l|c|c|c|}
\hline Moment & U.S. data & Lucas & Svensson \\
\hline$\rho\left[\gamma_{t}, \mu_{t}\right]$ & $0.336(0.112)$ & 0.332 & 0.332 \\
\hline$\rho\left[v_{t}, \gamma_{t}\right]$ & $-0.317(0.085)$ & $-0.285^{* *}$ & -0.014 \\
$\rho\left[v_{t}, \mu_{t}\right]$ & $-0.618(0.107)$ & 0.808 & 0.937 \\
$\rho\left[v_{t}, \pi_{t}\right]$ & $-0.030(0.241)$ & 0.817 & 0.697 \\
$\rho\left[v_{t}, i_{t}\right]$ & $0.224(0.186)$ & 0.999 & 0.961 \\
$\rho\left[\pi_{t}, \gamma_{t}\right]$ & $-0.335(0.147)$ & $-0.573^{*}$ & $-0.451^{* *}$ \\
$\rho\left[\pi_{t}, \mu_{t}\right]$ & $0.329(0.109)$ & $0.452^{*}$ & $0.487^{*}$ \\
$\rho\left[\pi_{t}, i_{t}\right]$ & $0.714(0.126)$ & $0.816^{* *}$ & $0.775^{* *}$ \\
$\rho\left[i_{t}, \gamma_{t}\right]$ & $-0.171(0.168)$ & $-0.285^{* *}$ & $-0.284^{* *}$ \\
$\rho\left[i_{t}, \mu_{t}\right]$ & $0.194(0.149)$ & 0.807 & 0.807 \\
\hline
\end{tabular}

Notes to tables: Standard erros in parenthesis. $\gamma$ is output growth rate $\Gamma$ $\mu$ is money growth rate $\Gamma v$ is money velocity $\Gamma \pi$ is inflation and $i$ is nominal interest rate.

** Within one standard error of the sample value.

* Within two standard errors of the sample value. 
Table 11

Models Results vs. Sample Values: Quarterly DataГ1959-96

Means and Standard Deviations

\begin{tabular}{|l|c|c|c|}
\hline Moment & U.S. data & Lucas & Svensson \\
\hline$E\left[\gamma_{t}\right]$ & $1.005(0.001)$ & $1.005^{* *}$ & $1.005^{* *}$ \\
$\sigma\left[\gamma_{t}\right]$ & $0.010(0.001)$ & $0.010^{* *}$ & $0.010^{* *}$ \\
$E\left[\mu_{t}\right]$ & $1.015(0.001)$ & $1.015^{* *}$ & $1.015^{* *}$ \\
$\sigma\left[\mu_{t}\right]$ & $0.009(0.001)$ & $0.009^{* *}$ & $0.009^{* *}$ \\
\hline$E\left[v_{t}\right]$ & $1.735(0.014)$ & $1.738^{* *}$ & $1.747^{* *}$ \\
$\sigma\left[v_{t}\right]$ & $0.098(0.013)$ & 0.034 & 0.048 \\
$E\left[\pi_{t}\right]$ & $0.011(0.001)$ & $0.010^{* *}$ & $0.010^{* *}$ \\
$\sigma\left[\pi_{t}\right]$ & $0.006(0.001)$ & 0.023 & 0.029 \\
$E\left[i_{t}\right]$ & $0.015(0.001)$ & $0.017^{*}$ & $0.017^{*}$ \\
$\sigma\left[i_{t}\right]$ & $0.006(0.001)$ & 0.001 & 0.001 \\
\hline
\end{tabular}

Table 12

Models Results vs. Sample Values: Quarterly DataT1959-96

Correlations

\begin{tabular}{|l|c|c|c|}
\hline Moment & U.S. data & Lucas & Svensson \\
\hline$\rho\left[\gamma_{t}, \mu_{t}\right]$ & $0.204(0.065)$ & $0.216^{* *}$ & $0.216^{* *}$ \\
\hline$\rho\left[v_{t}, \gamma_{t}\right]$ & $-0.182(0.060)$ & 0.041 & 0.095 \\
$\rho\left[v_{t}, \mu_{t}\right]$ & $-0.474(0.080)$ & 0.984 & 0.992 \\
$\rho\left[v_{t}, \pi_{t}\right]$ & $0.006(0.124)$ & 0.614 & 0.564 \\
$\rho\left[v_{t}, i_{t}\right]$ & $0.241(0.125)$ & 1.000 & 0.998 \\
$\rho\left[\pi_{t}, \gamma_{t}\right]$ & $-0.235(0.110)$ & -0.513 & $-0.435^{*}$ \\
$\rho\left[\pi_{t}, \mu_{t}\right]$ & $0.232(0.076)$ & 0.510 & 0.494 \\
$\rho\left[\pi_{t}, i_{t}\right]$ & $0.639(0.067)$ & $0.614^{* *}$ & $0.584^{* *}$ \\
$\rho\left[i_{t}, \gamma_{t}\right]$ & $-0.196(0.103)$ & 0.042 & 0.042 \\
$\rho\left[i_{t}, \mu_{t}\right]$ & $0.128(0.086)$ & 0.984 & 0.984 \\
\hline
\end{tabular}

Notes to tables: Standard erros in parenthesis. $\gamma$ is output growth rate $\Gamma$ $\mu$ is money growth rate $\Gamma v$ is money velocity $\Gamma \pi$ is inflation and $i$ is nominal interest rate.

** Within one standard error of the sample value.

* Within two standard errors of the sample value. 
Table 13

Expected Welfare Cost of Inflation

\begin{tabular}{|c|c|c|}
\hline$E(\mu)$ & No uncertainty & Uncertainty \\
\hline$\beta$ & 0.000 & $0.008(.018)$ \\
1.00 & 0.000 & $0.019(.028)$ \\
1.03 & 0.391 & $0.322(.076)$ \\
1.06 & 0.865 & $0.817(.092)$ \\
1.10 & 1.354 & $1.320(.103)$ \\
1.20 & 2.271 & $2.251(.110)$ \\
1.30 & 2.979 & $2.965(.108)$ \\
1.40 & 3.575 & $3.564(.103)$ \\
\hline
\end{tabular}

Table 14

Expected Money Velocity

\begin{tabular}{|c|c|c|}
\hline$E(\mu)$ & No uncertainty & Uncertainty \\
\hline$\beta$ & 1.000 & $1.008(.016)$ \\
1.00 & 1.000 & $1.017(.026)$ \\
1.03 & 1.364 & $1.300(.071)$ \\
1.06 & 1.809 & $1.764(.087)$ \\
1.10 & 2.273 & $2.241(.098)$ \\
1.20 & 3.155 & $3.136(.107)$ \\
1.30 & 3.848 & $3.834(.106)$ \\
1.40 & 4.439 & $4.426(.103)$ \\
\hline
\end{tabular}

Table 15

Expected Nominal Interest Rate

\begin{tabular}{|c|c|c|}
\hline$E(\mu)$ & No uncertainty & Uncertainty \\
\hline$\beta$ & 0.000 & $0.000(-)$ \\
1.00 & 0.010 & $0.008(-)$ \\
1.03 & 0.040 & $0.037(.004)$ \\
1.06 & 0.070 & $0.067(.007)$ \\
1.10 & 0.111 & $0.108(.009)$ \\
1.20 & 0.212 & $0.210(.014)$ \\
1.30 & 0.313 & $0.311(.017)$ \\
1.40 & 0.414 & $0.412(.019)$ \\
\hline
\end{tabular}

Notes to tables: Standard erros in parenthesis. 